Y. Fu, W. Zuo, M. Wetter, J. W. VanGilder, X. Han, D. Plamondon 2019. “Equation-

Based Object-Oriented Modeling and Simulation for Data Center Cooling: A Case

Study." Energy and Buildings, 186, pp. 108-125. DOI: 10.1016/j.enbuild.2019.01.018

\title{
Equation-Based Object-Oriented Modeling and Simulation for Data Center Cooling:
}

\section{A Case Study}

Yangyang Fu', Wangda Zuo a,", Michael Wetter ${ }^{\mathrm{b}}$, Jim W. VanGilder ${ }^{\mathrm{c}}, \mathrm{Xu} \mathrm{Han}^{\mathrm{a}}$, David Plamondon $^{\mathrm{d}}$

${ }^{a}$ Department of Civil, Architectural and Environmental Engineering, University of Colorado at Boulder, Boulder, CO, 80309, USA

${ }^{\mathrm{b}}$ Building Technology and Urban Systems, Lawrence Berkeley National Laboratory, Berkeley, CA, 94720, USA

${ }^{\mathrm{c}}$ Schneider Electric, Andover, MA, 01810, USA

${ }^{\mathrm{d}}$ University of Massachusetts Medical School, Worcester, MA, 01655, USA

* Corresponding Author: wangda.zuo@colorado.edu

\begin{abstract}
Data center cooling accounts for about $1 \%$ of electricity usage in the United States. Computer models are pivotal in designing and operating energy-efficient cooling systems. Compared to conventional building performance simulation programs, the equation-based object-oriented modeling language Modelica is an emerging approach that can enable fast prototyping and dynamic simulation of cooling systems. In this case study, we first modeled the cooling and control systems of an actual data center located in Massachusetts using the open-source Modelica Buildings library, and then calibrated a baseline model based on measurement data. The simulation of the baseline model identified several operation-related issues in the cooling and control systems, such as degraded cooling coils, improper dead band in control settings, and simultaneous cooling and heating in air handlers. Afterwards, we used a sequential search technique as well as an optimization scheme to investigate the energy saving potentials for different energy efficiency measures aiming to address the abovementioned issues. Simulation results show potential energy savings up to $24 \%$ by resolving identified control-related issues and optimizing the supply air temperature.
\end{abstract}

Keywords: Equation-Based, Object-Oriented, Modelica, Data Center

\section{Introduction}

Data centers are critical, energy-intensive infrastructure that support the fast growth of the information technology (IT) industry and the transformation of the economy at large [1]. In 2010 data centers consumed about $1.1 \%$ to $1.5 \%$ of the total worldwide electricity and about $1.7 \%$ to 
$2.2 \%$ of United States electricity [2]. The energy in data centers is mainly consumed by two parts: IT equipment (e.g., servers, storage, network, etc.) and infrastructure (e.g., cooling system). The latter usually accounts for about half of the total energy consumption in a typical data center [3]. As a result, nearly $1 \%$ of the electricity is consumed by data center cooling in the United States.

Data center cooling is provided by a dynamic energy system with both system-level and equipment-level controls. Typically, the cooling system consists of water and air loops, various heat and mass transfer equipment, electrical and control devices. The time constants of the data center cooling system vary from seconds (e.g., control system) to hours (e.g., thermal storage). Their time evolution can be described in the continuous time domain, the discrete time domain, and the discrete event domain [4]. Furthermore, the data center cooling system interacts with both inside and outside conditions, such as varying IT loads and local weather conditions. When, where and how the workload is executed in the data center has significant influence on the cooling system [5]. The local weather conditions also impact the efficiency and operational states of the data center cooling systems [6,7]. Jones [8] outlined seven strategies and directions that should lead to improved energy efficiency of data centers, including the use of dynamic controls for the IT load and cooling system.

Many conventional building performance simulation tools have been exploited to model the energy flow in a data center. Pan et al. [9] developed an energy simulation model for two office buildings with data centers in EnergyPlus [10] to evaluate potential retrofit energy savings. Kummert et al. [11] modeled and analyzed the system inertia of a data center cooling system using TRNSYS [12]. Kuei-Peng et al. [13] applied eQUEST developed with the DOE-2 framework to explore the airside free cooling energy efficiency of data centers in 17 worldwide climate zones.

The conventional simulation tools, however, have exposed several challenges in modeling, simulating and optimizing data center cooling systems. Modeling data center cooling systems may result in a large, complex system model. Managing such large and complex models with these conventional tools can be difficult and time consuming [14]. In addition, those tools have limited capacity when it comes to control designs and evaluations. For instance, EnergyPlus adopts idealized controls to reduce computation time. Although TRNSYS has dynamic control models, its constant time step poses numerical challenges [15]. Further, conventional tools often intertwine model equations and numerical solvers in their source codes; this makes it difficult to extend these programs to support control-oriented cases [16]. Although many case studies have been conducted for data center cooling systems using those tools, they focused on either cooling equipment/system design and retrofit [17-20] or thermal management in the data center room [21-24]. According to the authors' knowledge, there is no case study focusing on the evaluation of the control of the cooling system (such as dead band settings) in an actual data center cooling system. The data center has a large constant internal load, while the office building's cooling load changes over time. This different load profile makes the operation of the data center cooling system different than the other building cooling system and provides a unique opportunity for controls evaluation and optimization.

The equation-based, object-oriented language Modelica [25] can be used to address the abovementioned issues [26]. The Modelica Buildings library has been developed to support various use cases related to Heating Ventilation and Air Conditioning (HVAC) systems in buildings [26, 27]. The Buildings library is an open-source, free library with component and system models for building energy and control systems. The library is also accompanied by Python modules that can be used to automate simulations and post-processing of simulation results. 
Besides the conventional energy analysis, this library can also support rapid prototyping [28, 29], modeling of arbitrary HVAC system topologies [28], model-based optimal control [6, 7], evaluation of the stabilization of feedback control and fault detection and diagnostics at the whole building system level $[14,30,31]$, and coupled simulation between the cooling system and the room airflow [32-34].

This paper aims to conduct a case study applying Modelica Buildings library to evaluate the dynamic cooling system for a data center located at the University of Massachusetts Medical School in Massachusetts, United States. In this case study, we demonstrate two benefits of Modelica-based modeling: fast prototyping by hierarchical modeling approach, dynamic evaluations of discrete control involving delay time and dead band. The whole paper is organized as follows: Section 2 gives a detailed description of the analyzed cooling and control systems, including the system configurations and different control strategies. Section 3 shows the management of the complex, large system model through a hierarchical modeling approach. The Modelica models are then calibrated using on-site measurement data in Section 4. In Section 5, we first identify several energy and control related issues in the baseline system through an annual simulation. Then we propose different energy efficiency measures (EEMs) to address the identified issues. A sequential search technique is applied to identify the combination of the most costeffective EEMs in terms of energy savings and life cycle cost (LCC). After that, an optimization of the supply air temperature for the best EEMs is performed to evaluate the energy saving potentials. Conclusions are presented in Section 6.

\section{System Description}

The data center analyzed operates 24 hours per day, 365 days per year. The data center room has a floor area of $687 \mathrm{~m}^{2}$ with a white space height of $3.35 \mathrm{~m}$. The room contains 138 IT racks and 12 floor-mounted power distribution units. This case study only focuses on the cooling and control system, and the room-side air distribution management is not considered.

\subsection{Cooling System}

A primary-only chilled water system with airside economizers (ASEs) is used to provide cooling for the data center room, as shown in Figure 1. The size of detailed components is listed in Table 1. The current cooling load of the data center is about $316 \mathrm{~kW}$. Two identical water-cooled chillers with a design coefficient of performance (COP) of 5.8 work in a Lead/Lag configuration to equalize their runtime. Each chiller has two variable-speed compressors. Two identical cooling towers with variable-speed fans eject the heat from the condenser water loop to the environment. Two chilled water pumps operate with variable speed drives, while two condenser water pumps work at a constant speed. Two Air Handler Units (AHUs) provide cool air to the data center white space. Each AHU consists of an array of 12 variable-speed supply air fans arranged in a parallelflow configuration. The cool supply air is delivered to cold aisles through an underfloor plenum. The hot IT exhaust air is directed into open hot aisles, then enters a ceiling plenum, then mixing box, and finally returns to the AHUs. When the weather conditions allow, the ASEs are activated to mix the cold outdoor air and warm indoor air to provide precooling or free cooling. The activation and deactivation of ASEs are controlled by a cooling mode controller discussed in Section 2.2. 


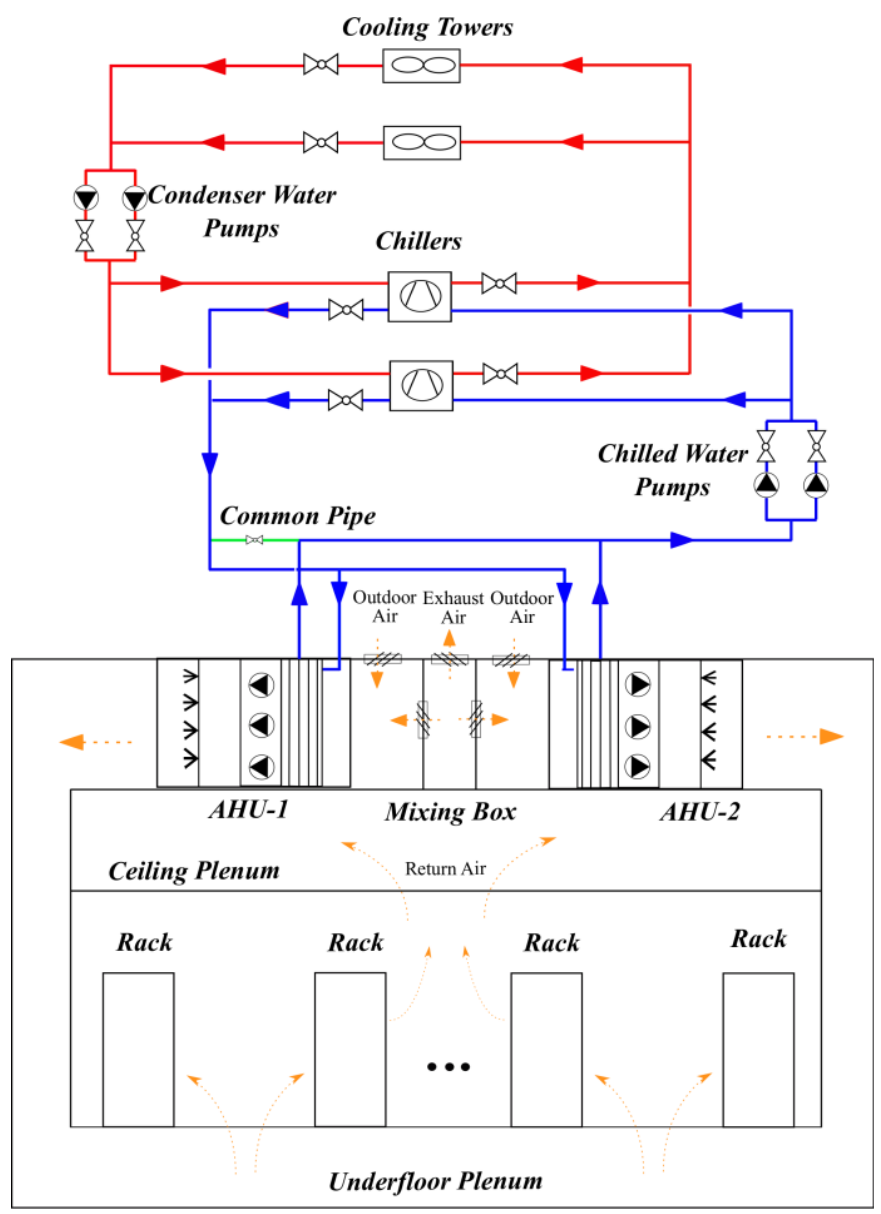

Figure 1. Schematic drawing of the cooling system in the data center

Table 1. Nominal information of components in the cooling system

\begin{tabular}{|c|c|c|c|c|c|}
\hline Equipment & Qty. & \multicolumn{2}{|c|}{ Nominal Equipment Information } & Unit & Value \\
\hline \multirow{12}{*}{ AHU } & \multirow{12}{*}{2} & \multirow{4}{*}{ Cooling Coil } & Air Flowrate & $\mathrm{m}^{3} / \mathrm{s}$ & 39.2 \\
\hline & & & Cooling Capacity & $\mathrm{kW}$ & 696 \\
\hline & & & Sensible Heat Ratio & - & 0.99 \\
\hline & & & Water Flowrate & $\mathrm{kg} / \mathrm{s}$ & 0.025 \\
\hline & & \multirow{2}{*}{ Heating Coil } & Qty. & - & 4 \\
\hline & & & Power & $\mathrm{kW}$ & 31.2 \\
\hline & & \multirow{2}{*}{ Steam Humidifier } & Qty. & - & 4 \\
\hline & & & Capacity & $\mathrm{kg} / \mathrm{s}$ & 0.019 \\
\hline & & \multirow{4}{*}{ Fan } & Qty. & - & 12 \\
\hline & & & Head & $\mathrm{Pa}$ & 622 \\
\hline & & & Power & $\mathrm{kW}$ & 3.42 \\
\hline & & & Flowrate & $\mathrm{m}^{3} / \mathrm{s}$ & 3.26 \\
\hline \multirow{3}{*}{ Chiller } & \multirow{3}{*}{2} & \multicolumn{2}{|c|}{ Nominal Capacity } & $\mathrm{kW}$ & 774 \\
\hline & & \multicolumn{2}{|c|}{ Design COP } & - & 5.8 \\
\hline & & Evaporator & Flowrate & $\mathrm{m}^{3} / \mathrm{s}$ & 0.028 \\
\hline
\end{tabular}




\begin{tabular}{|c|c|c|c|c|c|}
\hline & & & Design Outlet Temperature & ${ }^{\circ} \mathrm{C}$ & 10 \\
\hline & & \multirow{2}{*}{ Condenser } & Flowrate & $\mathrm{m}^{3} / \mathrm{s}$ & 0.026 \\
\hline & & & Design Inlet Temperature & ${ }^{\circ} \mathrm{C}$ & 29.4 \\
\hline & & \multirow{3}{*}{ Compressor } & Number & - & 2 \\
\hline & & & Speed Type & & Variable Speed \\
\hline & & & Power & $\mathrm{kW}$ & 67 \\
\hline \multirow{4}{*}{$\begin{array}{c}\text { Chiller Water } \\
\text { Pump }\end{array}$} & \multirow{4}{*}{2} & \multicolumn{2}{|c|}{ Head } & $\mathrm{mH}_{2} \mathrm{O}$ & 41 \\
\hline & & \multicolumn{2}{|c|}{ Power } & $\mathrm{kW}$ & 12 \\
\hline & & \multicolumn{2}{|c|}{ Flowrate } & $\mathrm{m}^{3} / \mathrm{s}$ & 0.028 \\
\hline & & \multicolumn{2}{|c|}{ Speed Type } & & Variable Speed \\
\hline \multirow{4}{*}{$\begin{array}{c}\text { Condenser } \\
\text { Water Pump }\end{array}$} & \multirow{4}{*}{2} & & Head & $\mathrm{mH}_{2} \mathrm{O}$ & 29.5 \\
\hline & & & ower & $\mathrm{kW}$ & 8 \\
\hline & & & wrate & $\mathrm{m}^{3} / \mathrm{s}$ & 0.026 \\
\hline & & & ed Type & & Constant Speed \\
\hline \multirow{5}{*}{$\begin{array}{l}\text { Cooling } \\
\text { Tower }\end{array}$} & \multirow{5}{*}{2} & & al Capacity & $\mathrm{kW}$ & 893 \\
\hline & & Design & ach Temperature & $\mathrm{K}$ & 4.4 \\
\hline & & & er of Cells & - & 1 \\
\hline & & & er of Fans & - & 1 \\
\hline & & & eed Type & & Variable Speed \\
\hline
\end{tabular}

\subsection{Control System}

The control system is composed of a system-level cooling mode control and an equipment-level control with various controllers, as shown in Figure 2. The solid lines show the hierarchical relationship between different controls. The dashed arrows describe the actual control signal flow between different controls. Based on the operational status and outdoor air conditions, the cooling mode controller selects a particular cooling source from the three available choices: chillers only, ASEs only, or both chillers and ASEs. The signal from the cooling mode controller is then sent to the equipment-level controllers to determine the appropriate operating point of individual equipment. 

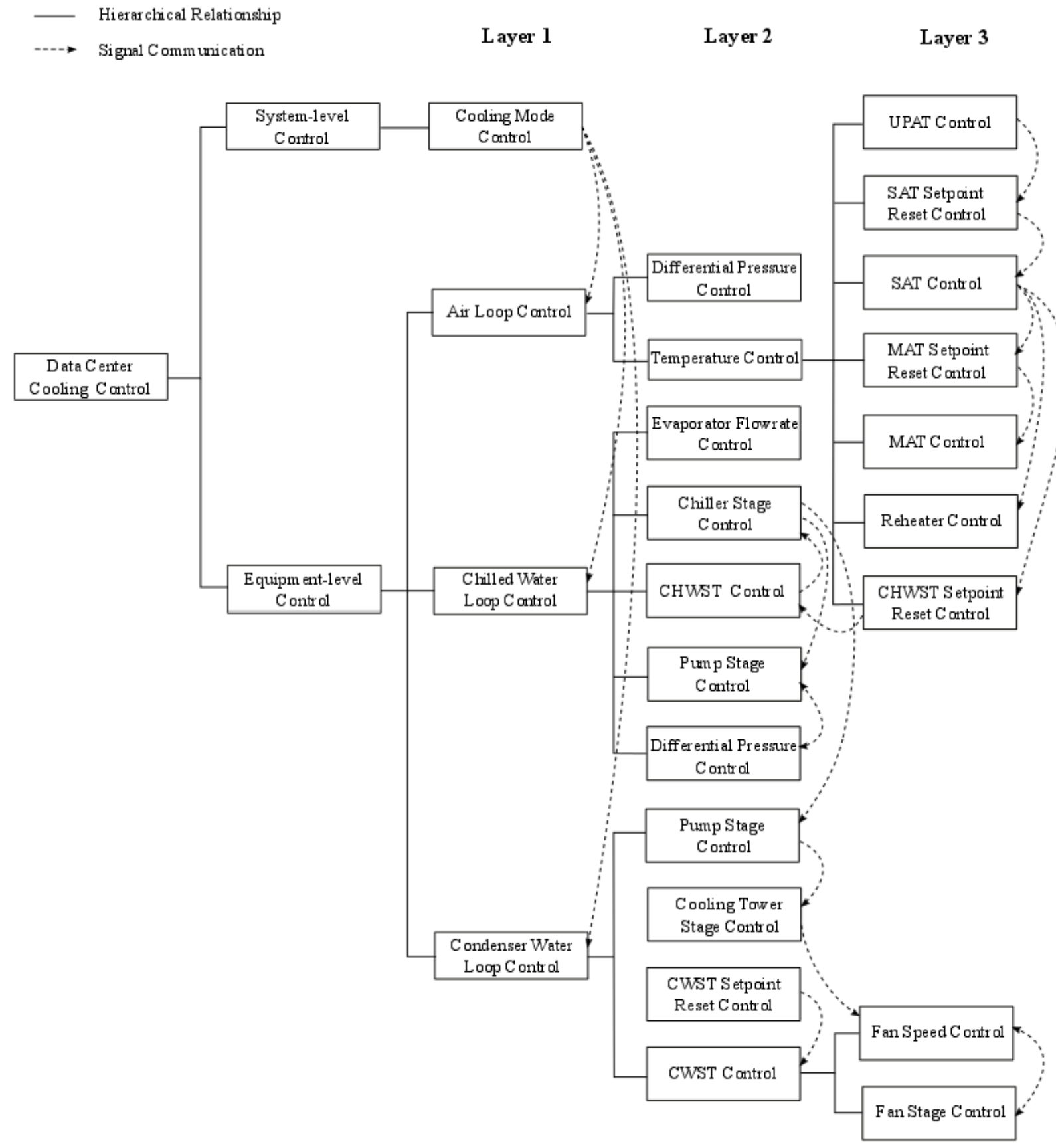

Figure 2. Structure of the data center cooling control

\subsubsection{System-level Control}

The chilled water system with ASEs can operate in three cooling modes to provide cooling for the data center: (1) Free Cooling (FC) mode, where only ASEs are activated; (2) Partial Mechanical Cooling (PMC) mode, where chillers and ASEs work simultaneously; and (3) Fully Mechanical Cooling (FMC) mode, where only chillers are utilized. As the cooling system has to operate 24 hours per day, 365 days per year, the system "off" state is not considered. The staging among the 
different cooling modes is controlled by prescribed transition conditions, which is described by a state graph shown in Figure 3.

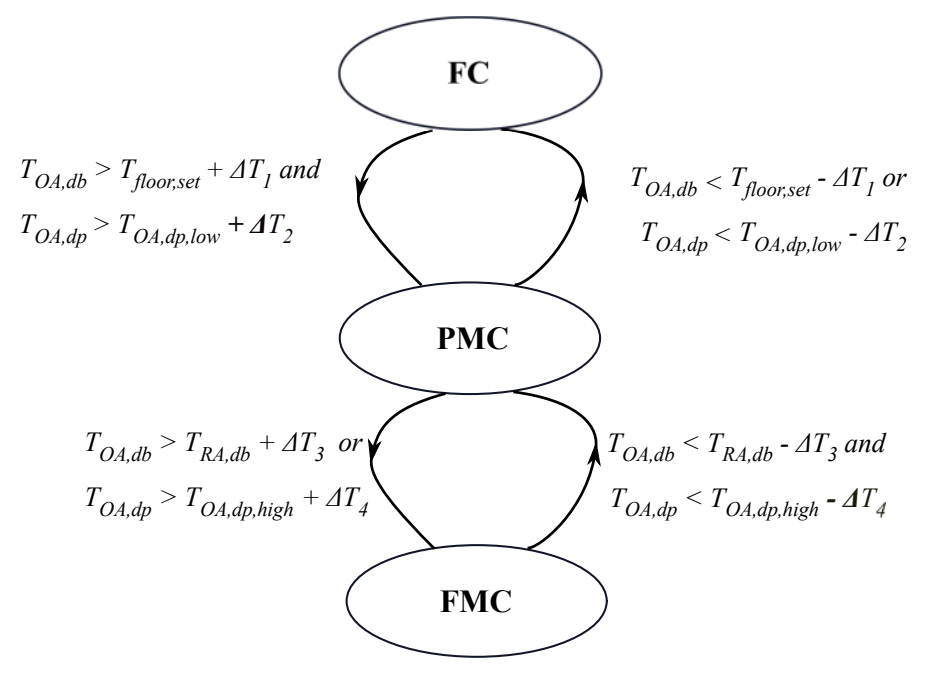

Figure 3. State graph of the cooling mode controller

The transition between FC and PMC mode is determined by air temperature setpoint in the underfloor plenum $T_{\text {floor, set }}$ and outdoor air conditions, such as dry bulb temperature, $T_{O A, d b}$, and dew point temperature $T_{O A, d p}$. The cooling system switches from FC to PMC mode, when

$$
T_{O A, d b}>T_{f l o o r, s e t}+\Delta T_{1} \text { and } T_{O A, d p}>T_{O A, d p, l o w}+\Delta T_{2},
$$

and from PMC to FC mode when

$$
T_{O A, d b}<T_{\text {floor,set }}-\Delta T_{1} \text { or } T_{O A, d p}<T_{O A, d p, l o w}-\Delta T_{2}
$$

where $T_{O A, d p, l o w}$ is the low cutoff limit for $T_{O A, d p}$, and $\Delta T_{1}$ and $\Delta T_{2}$ are temperature dead band settings.

The transition between PMC and FMC mode is governed by $T_{O A, d b}, T_{O A, d p}$, and data center return air temperature $T_{R A, d b}$. The cooling system switches from PMC to FMC mode when the following conditions are triggered:

$$
T_{O A, d b}>T_{R A, d b}+\Delta T_{3} \text { or } T_{O A, d p}>T_{O A, d p, \text { high }}+\Delta T_{4}
$$

and from FMC to PMC mode, when the following conditions are met:

$$
T_{O A, d b}<T_{R A, d b}-\Delta T_{3} \text { and } T_{O A, d p}<T_{O A, d p, h i g h}-\Delta T_{4}
$$

where $T_{O A, d p, \text { high }}$ is the high cutoff limit for $T_{O A, d p}$, and $\Delta T_{3}$ and $\Delta T_{4}$ are temperature dead band settings. The $T_{O A, d p}, T_{O A, d b}$, and $T_{R A, d b}$ are read from measured data. The $T_{\text {floor,set }}, T_{O A, d p, h i g h}$ and $T_{O A, d p \text {,low }}$ are set to $22.2^{\circ} \mathrm{C}, 12.75^{\circ} \mathrm{C}$, and $11.65^{\circ} \mathrm{C}$, respectively. The dead bands $\Delta T_{1}$ and $\Delta T_{3}$ are set to $1.1{ }^{\circ} \mathrm{C}$, and $\Delta T_{2}$ and $\Delta T_{4}$ are $0.55^{\circ} \mathrm{C}$. To prevent short-cycling, all the conditions must remain true for 2 minutes before switching to next state. 


\subsubsection{Equipment-level Control}

As shown in Figure 2, the equipment-level control consists of multiple layers with complicated interactions among different controllers. Layer 1 is designed to coordinate the operation of the three major fluid loops of the cooling system: air, chilled water, and condenser water. Each loop has multiple groups of different controls in Layer 2. For instance, the air loop has two groups of controls. One is to control the differential pressure in the underfloor plenum to ensure that a reasonable amount of air passes through the perforated tiles to the data center room. The other is designed for the temperature control. Some groups in Layer 2 also have multiple controllers (Layer 3 ) dedicated to different control objectives. For example, the condenser water supply temperature (CWST) control in the condenser water loop consists of controls for cooling tower fan staging and fan speed. The details are explained in a top-down approach from Layer 1 to Layer 3 as follows.

\subsubsection{Air Loop Control}

Air loop control includes the control for the underfloor plenum and AHUs. The average static pressure in the underfloor plenum is controlled at a setpoint of $12.4 \mathrm{~Pa}$ by modulating the AHU fan speed. The AHUs run all the time. The fans in each AHU are equipped with variable frequency drives and they are controlled to run at the same speed.

The temperature control in the air loop determines the supply air temperature (SAT) setpoint for AHUs, mixed air temperature (MAT) setpoint, outdoor air damper position, chilled water supply temperature (CHWST) setpoint, and control signals for the reheaters in the AHUs. The control strategies and interactions are schematically shown in Figure 4. The underfloor plenum air temperature (UPAT) is maintained at its setpoint $T_{\text {floor,set }}=22.2^{\circ} \mathrm{C}$ by resetting the SAT setpoint for AHUs in a range from $15.6{ }^{\circ} \mathrm{C}$ to $23.3^{\circ} \mathrm{C}$ using:

$$
y=\left\{\begin{aligned}
y_{r e f, 1}, & u<u_{r e f, 1} \\
\left(u-u_{r e f, 1}\right) \frac{y_{r e f, 2}-y_{r e f, 1}}{u_{r e f, 2}-u_{r e f, 1}}+y_{r e f, 1}, & u_{r e f, 1} \leq u \leq u_{r e f, 2} \\
y_{r e f, 2}, & u>u_{r e f, 2}
\end{aligned}\right.
$$

where $u$ and $y$ are input and output signals respectively. The $u_{r e f, 1}, u_{r e f, 2}, y_{r e f, 1}$, and $y_{r e f, 2}$ are predefined reference values. In this case, $u$ is the output of a proportional-integral-derivative (PID) controller (PID-1) and $u_{r e f, 1}=0, u_{r e f, 2}=1, y_{r e f, 1}=23.3^{\circ} \mathrm{C}$, and $y_{r e f, 2}=15.6^{\circ} \mathrm{C}$. It is worth mentions that (5) is also used by other controllers in Figure 4 but with different reference values for both input and output signals.

Using the reset SAT setpoint and measured SAT, two PID controllers (PID-2 and PID-3) are adopted to control the SAT for AHU- 1 and AHU-2, respectively. The output signal $y_{2}$ and $y_{3}$ from the two PID controllers, ranging from 0 to 1 , are then used in different control strategies under different cooling modes.

- In the FC mode, the SAT is maintained at its setpoint by adjusting the MAT setpoint. The maximum of the output signals $y_{2}$ and $y_{3}$ is used to reset the MAT setpoint within a range of $14.4^{\circ} \mathrm{C}$ to $25.3{ }^{\circ} \mathrm{C}$ through (5). The MAT is then maintained at its setpoint by adjusting the outdoor air dampers through a PID controller (PID-4). 
- In the PMC and FMC modes, the system will either reset the CHWST setpoint or activate reheaters to maintain the SAT. To reset the CHWST setpoint, the output signals $y_{2}$ and $y_{3}$ are mapped to the CHWST setpoint within the range of $7.8^{\circ} \mathrm{C}$ to $12.2^{\circ} \mathrm{C}$. The minimum of the mapped setpoints CHWST $_{\text {set }, 1}$ and $\mathrm{CHWST}_{\text {set }, 2}$ is then sent to the chillers as the CHWST setpoint. For the reheaters, $y_{2}$ and $y_{3}$ are mapped to a control signal ranging from 0 to 1 in order to adjust the power of reheaters in AHU-1 and AHU-2, respectively. Take AHU-1 as an example. The reference values in the CHWST setpoint reset control are set to $u_{r e f, 1}=0.4, u_{r e f, 2}=1, y_{r e f, 1}=12.2^{\circ} \mathrm{C}$ and $y_{r e f, 2}=7.8^{\circ} \mathrm{C}$. In the reheater control, they are set to $u_{r e f, 1}=0, u_{r e f, 2}=0.4, y_{r e f, 1}=1$ and $y_{r e f, 2}=0$. When the output signal $y_{2}$ of PID-2 is less than 0.4, the CHWST setpoint reset control is deactivated, and the reheater control is activated. Reverse actions are triggered when $y_{2}$ is greater than 0.4 .

\subsubsection{Chilled Water Loop}

Chilled water loop control is composed of controls for the chillers and chilled water pumps. At the current cooling load, only one chiller is needed when FMC or PMC mode is activated. The chilled water pumps are set up to run one pump per chiller. The speed of the chilled water pumps is modulated by a PI controller to maintain a constant pressure difference of $206 \mathrm{kPa}$ between the inlet and the outlet of the chiller evaporators. The bypass valve in the common leg is regulated by a PI controller to maintain a constant flowrate through the evaporators. 
UPAT Control SAT Setpoint Reset Control

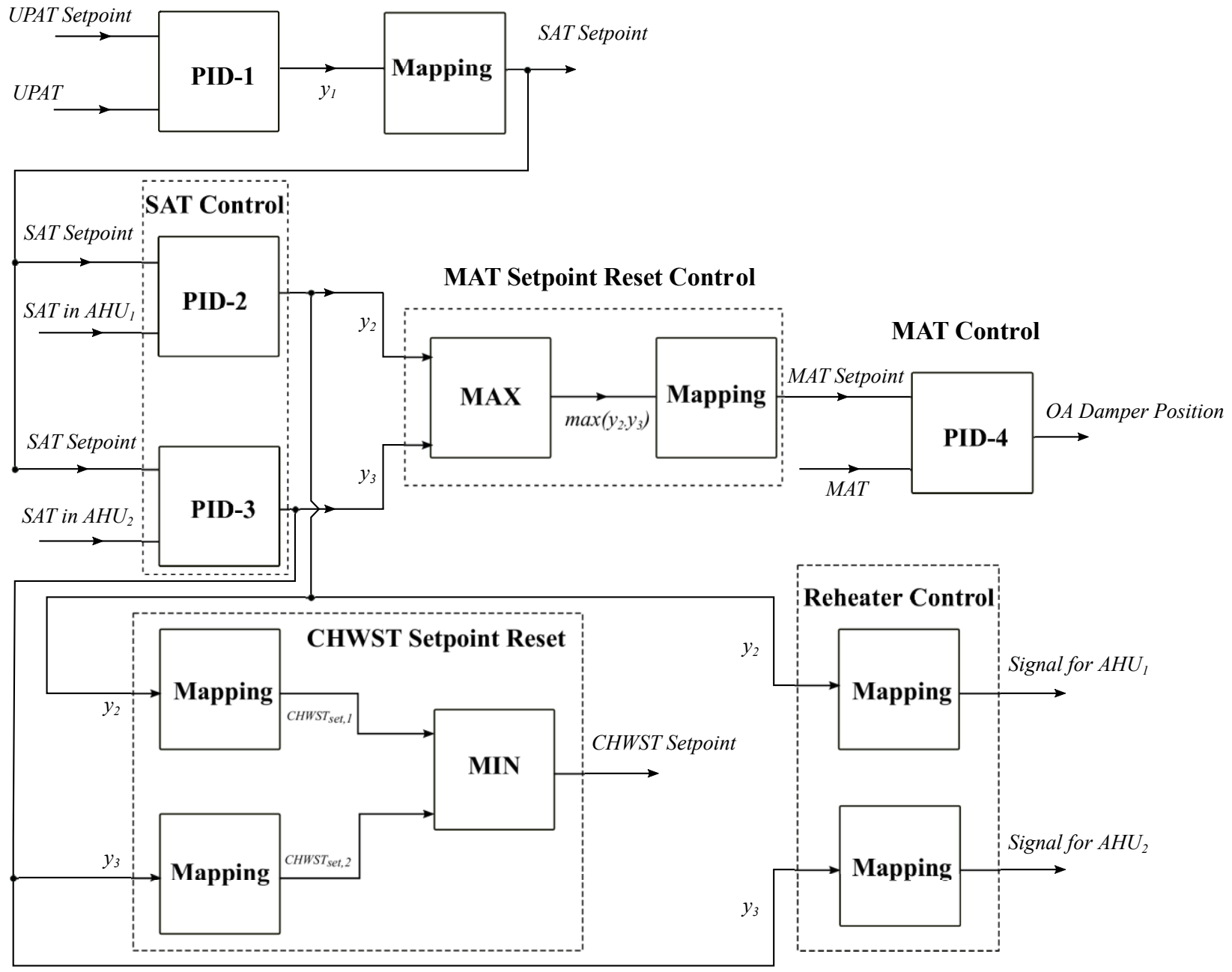

Figure 4. Temperature control for the air loop

\subsubsection{Condenser Water Loop}

Condenser water loop control includes controls for the condenser water pumps and cooling towers. The condenser water pumps and cooling towers are staged based on the number of operating chillers: one condenser water pump and cooling tower is commanded on if one chiller is required. The CWST setpoint is reset from $21.1^{\circ} \mathrm{C}$ to $29.4^{\circ} \mathrm{C}$ as the outdoor air wet bulb temperature increases from $17.2{ }^{\circ} \mathrm{C}$ to $25.6^{\circ} \mathrm{C}$ using the mapping algorithm in (5).

The speed and number of operating fans in cooling towers are manipulated to control the CWST at its setpoint. The fan speed is adjusted by a PI controller to reduce the difference between the CWST and the setpoint, and the number of working fans is determined as follows:

One additional fan is switched on if

$$
T_{c w s}>T_{c w s, s e t}+\Delta T, \text { and } S P_{\text {fan }}>S P_{\text {high }}+\Delta S P,
$$

and switched off if 


$$
T_{c w s}<T_{c w s, s e t}-\Delta T, \text { or } S P_{f a n}<S P_{l o w}-\Delta S P
$$

where $T_{c w s}$ is condenser water supply temperature, $T_{c w s, s e t}$ is condenser water supply temperature setpoint, $\Delta T$ is temperature dead band, $S P_{\text {fan }}$ is cooling tower fan speed, $S P_{\text {high }}, S P_{\text {low }}$ are the high and low threshold of the fan speed,, and $\triangle S P$ is the fan speed dead band. In this case study, $\Delta T$ is set to $1{ }^{\circ} \mathrm{C}, S P_{\text {high }}$ is set to $0.8, S P_{\text {low }}$ is set to 0.4 , and $\Delta S P$ is set to 0.1 . To prevent shortcycling, the conditions described in (6) an (7) need to remain true for 5 minutes before the control actions are triggered.

\section{Modelica Models}

The cooling and control systems are modeled using the Modelica language. The Modelica Buildings library version 5.0.0 provides models for data center cooling systems [35]. The following sections illustrate how to perform modeling and simulation by taking advantage of object-oriented, equation-based modeling. We first introduce the implementation of equipment models and control system models, and then demonstrate the system model by integrating the models of equipment and control.

\subsection{Component Models for the Cooling System}

Most components of the cooling system are modeled directly using the existing models in the Modelica Buildings library. The pipes and ducts are modeled using Buildings.Fluid.FixedResistances.PressureDrop, which is a flow resistance with a fixed flow coefficient. The cooling tower is modeled using Buildings.Fluid.HeatExchangers.CoolingTowers.YorkCalc, which uses a polynomial to predict the approach temperature for the cooling tower at off-design conditions. The performance of chiller compressor is predicted using the DOE-2 electrical chiller model [36], which consists of 3 performance curves: CAPFT - a curve that represents available cooling capacity as a function of the evaporator and condenser temperature, EIRFT - a curve that represents the full load efficiency as function of the evaporator and condenser temperature, and EIRFPLR - a curve that represents the efficiency as a function of the part-load ratio. The head and power of the pumps/fans are represented as a quadratic equation in terms of the flowrate. Detailed curves are shown in Table 2, where $T_{w b}$ is the wet bulb temperature, $T_{r a n}$ is the range temperature defined as the temperature difference between the supply and return condenser water, $r$ is the water to air mass flowrate ratio, $T_{c h w s}$ is the chilled water supply temperature, $T_{c w s}$ is the condenser water supply temperature, $P L R$ is the part load ratio, $Q$ is the flowrate of water or air, $H$ is the head of the pump/fan, $P$ is the power of the pump/fan. $a, b, c, d, e, f$ are the coefficients that needed to be calibrated for each model.

For component models that are not included in the Buildings library, we constructed the models based on Modelica standard library (Version 3.2.2 Build 3) and Buildings library (Version 5.0.0). For example, the Buildings library has no model for a chiller that is equipped with two variablespeed compressors. However, such a dual-compressor chiller model can be built quickly by utilizing the existing chiller models in the Buildings library. As shown in Figure 5, we instantiated an electric chiller object model (Buildings.Fluid.Chillers.ElectricEIR) twice to represent two variable-speed compressors, denoted as "Compressor 1" and "Compressor 2", respectively. Each compressor has its own performance curves to calculate the off-design performance. 
Table 2. Performance curves for major cooling equipment

\begin{tabular}{|c|c|}
\hline Model & Performance Curves \\
\hline $\begin{array}{c}\text { Cooling } \\
\text { Tower }\end{array}$ & $\begin{aligned} T_{a p p}=a_{1}+ & a_{2} T_{w b}+a_{3} T_{w b}^{2}+a_{4} T_{r a n}+a_{5} T_{r a n} T_{w b}+a_{6} T_{w b}^{2} T_{r a n}+a_{7} T_{r a n}^{2} \\
& +a_{8} T_{w b} T_{r a n}^{2}+a_{9} T_{w b}^{2} T_{r a n}^{2}+a_{10} r+a_{11} T_{w b} r+a_{12} T_{w b}^{2} r \\
& +a_{13} T_{r a n} r+a_{14} T_{w b} T_{r a n} r+a_{15} T_{w b}^{2} T_{r a n} r+a_{16} T_{r a n}^{2} r \\
& +a_{17} T_{w b} T_{r a n}^{2} r+a_{18} T_{w b}^{2} T_{r a n}^{2} r+a_{19} r^{2}+a_{20} T_{w b} r^{2} \\
& +a_{21} T_{w b}^{2} r^{2}+a_{22} T_{r a n} r^{2}+a_{23} T_{w b} T_{r a n} r^{2}+a_{24} T_{w b}^{2} T_{r a n} r^{2} \\
& +a_{25} T_{r a n}^{2} r^{2}+a_{26} T_{w b} T_{r a n}^{2} r^{2}+a_{27} T_{w b}^{2} T_{r a n}^{2} r^{2}\end{aligned}$ \\
\hline Chiller & $\begin{array}{c}\text { CAPFT }=b_{1}+b_{2} T_{c h w s}+b_{3} T_{c h w s}^{2}+b_{4} T_{c w s}+b_{5} T_{c w s}^{2}+b_{6} T_{c h w s} T_{c w s} \\
\text { EIRFT }=c_{1}+c_{2} T_{c h w s}+c_{3} T_{c h w s}^{2}+c_{4} T_{c w s}+c_{5} T_{c w s}^{2}+c_{6} T_{c h w s} T_{c w s} \\
\text { EIRFPLR }=d_{1}+d_{2} P L R+d_{3} P L R^{2}\end{array}$ \\
\hline Pump/Fan & $\begin{aligned} H & =e_{1}+e_{2} Q+e_{3} Q^{2} \\
P & =f_{1}+f_{2} Q+f_{3} Q^{2}\end{aligned}$ \\
\hline
\end{tabular}

A stage control is also included to activate the compressors based on load conditions and other control commands. When the chiller is commanded on, one compressor will be turned on immediately. The second compressor is staged on if

$$
T_{\text {chws }}>T_{\text {chws,set }}+\Delta T, \text { and } \Delta t_{o f f}>\Delta t_{t h r},
$$

and staged off if

$$
T_{\text {chws }}<T_{\text {chws,set }}-\Delta T \text {, and } \Delta t_{o n}>\Delta t_{t h r}
$$

where $T_{\text {chws }}$ is the chilled water supply temperature, $T_{\text {chws,set }}$ is the chilled water supply temperature setpoint, $\Delta T$ is a temperature dead band of $1^{\circ} \mathrm{C}, \Delta t_{\text {off }}$ is the elapsed time since the compressor was off, $\Delta t_{\text {on }}$ is the passing of time after the compressor was commanded on last time, and $\Delta t_{t h r}$ is the time threshold (e.g. 20 minutes in this case) to prevent short cycling of compressors. 


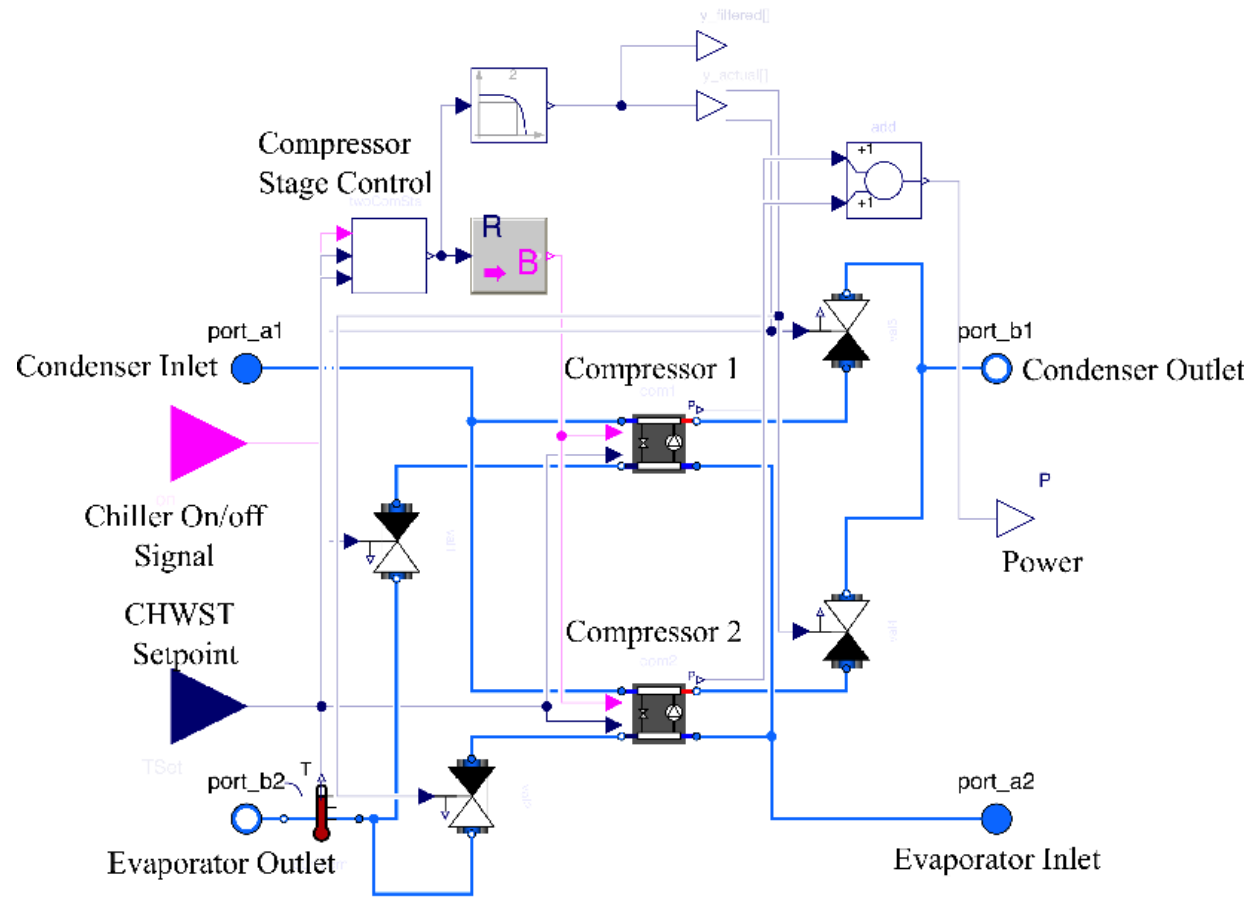

Figure 5. Diagram of Modelica model for a chiller with two variable speed compressors

\subsection{Control System Model}

\subsubsection{Cooling Mode Control}

Figure 6 shows the Modelica implementation of the cooling mode control described in Figure 2. On the left are the connectors for the control input signals expressed as real numbers, including $T_{\text {floor,set }}, T_{O A, d b}, T_{O A, d p}$, and $T_{R A, d b}$. In the middle is the state graph implemented using the Modelica state graph package. On the right are signal conversions from Boolean to Integer signals, followed by an Integer connector, which outputs the control signal of the cooling modes.

There are three states in the cooling mode controller, indicated by the squared block icons in the middle of Figure 6. The states are FC, PMC, and FMC mode. The initial state is set to FMC mode when simulation starts. The transitions between the states are represented by the horizontal black bars, and each transition has exactly one preceding state and one succeeding state. 


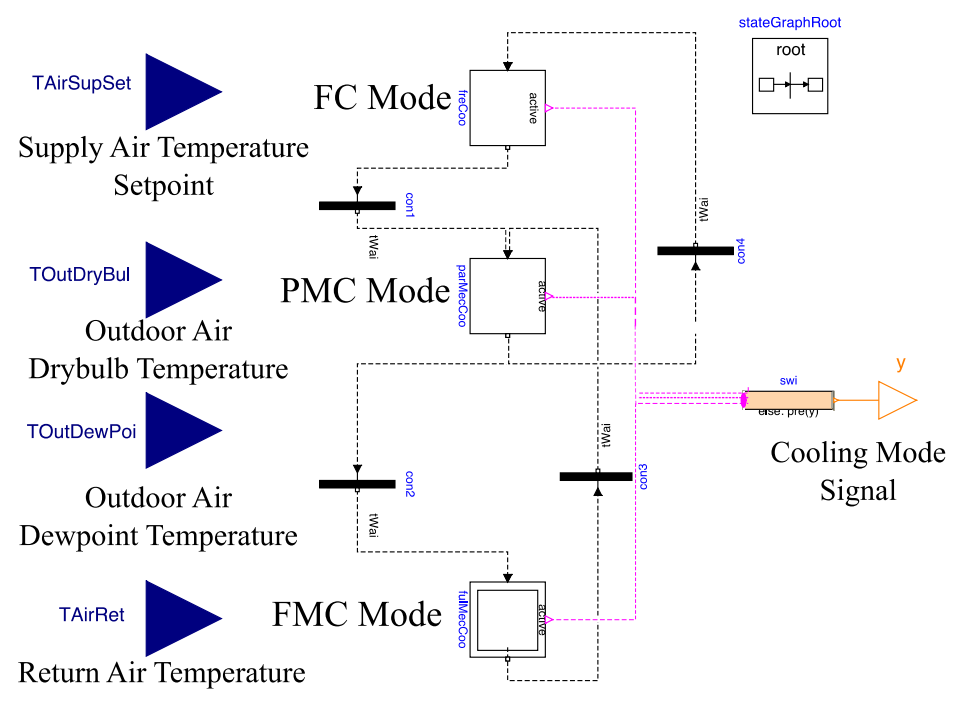

Figure 6. Diagram of Modelica models for the cooling mode control

\subsubsection{Equipment-Level Controls}

The hierarchy of the equipment-level controls described in Error! Reference source not found. is implemented in Modelica by a bottom-up approach. We first declare the equipment controls at Layer 3 as Modelica classes. Then we instantiate these classes and encapsulate their instances layer by layer (from Layer 3 to Layer 1) to formulate the control models for the different loops in Layer 1 .

Figure 7 shows a part of the hierarchical models of the condenser water loop control. Each icon encapsulates a model that may encapsulate other models. Figure 7(a) shows the model for the condenser water loop control in Layer 1, including pump stage control, cooling tower stage control, CWST setpoint reset control, and CWST control, as indicated in the dash boxes. Figure 7(b) shows the implementation of CWST control in Layer 2. The CWST control model further encapsulates the instantiations of fan stage control model and the fan speed control model in Layer 3. For instance, Figure 7(c) demonstrates the implementation of the fan speed control model. Taking advantages of object inheritance, and instantiation in the object-oriented Modelica, this hierarchical modeling structure allows users to manage the complexity of large models, and to assemble system models as one would connect components in an actual system. This structure also facilitates debugging and verification of component models. For example, a lower-level model is first debugged and verified, and then instantiated in a higher-level model, which can help identify modelling errors at the early stage of the model development. 


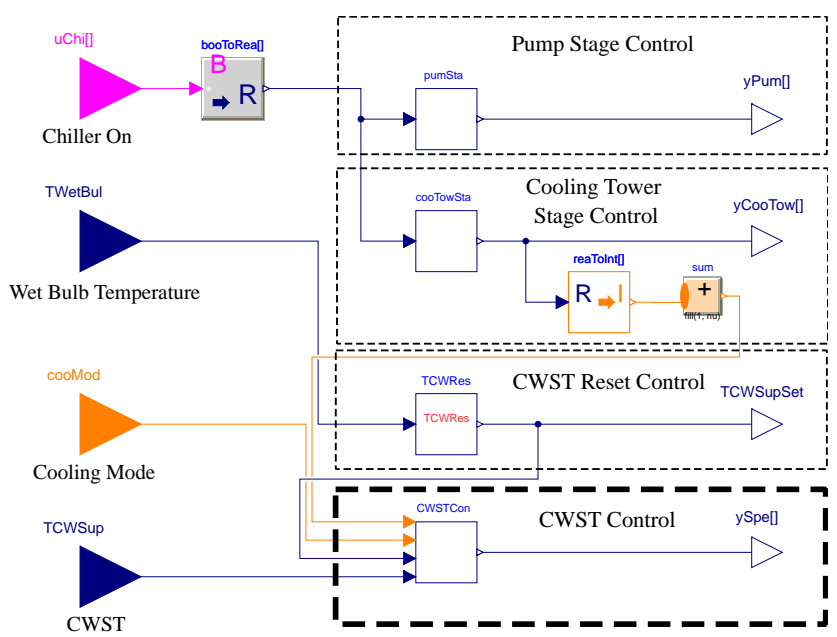

(a) Diagram of the condenser water loop control

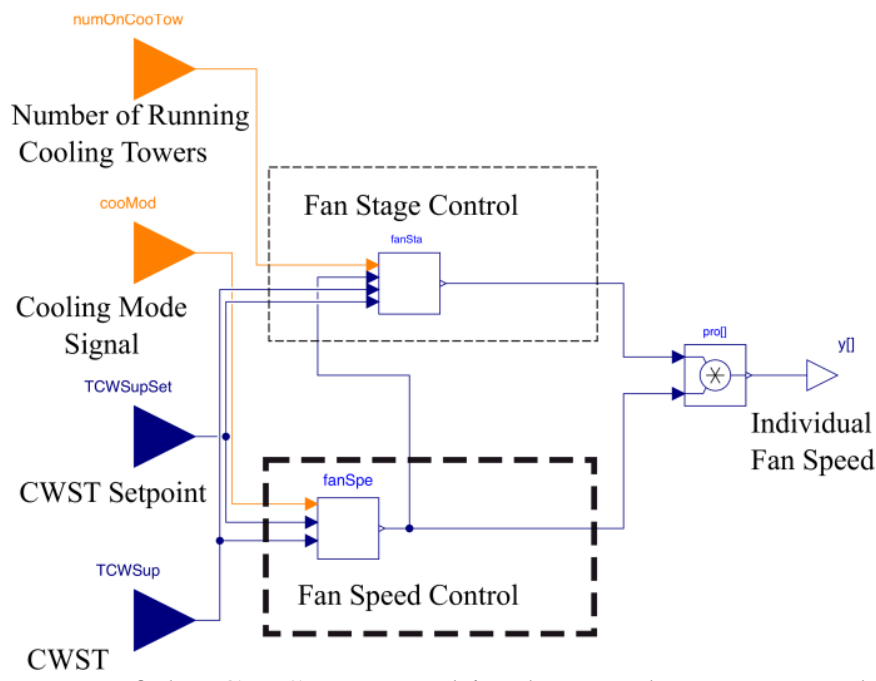

(b) Diagram of the CWST control in the condenser water loop control

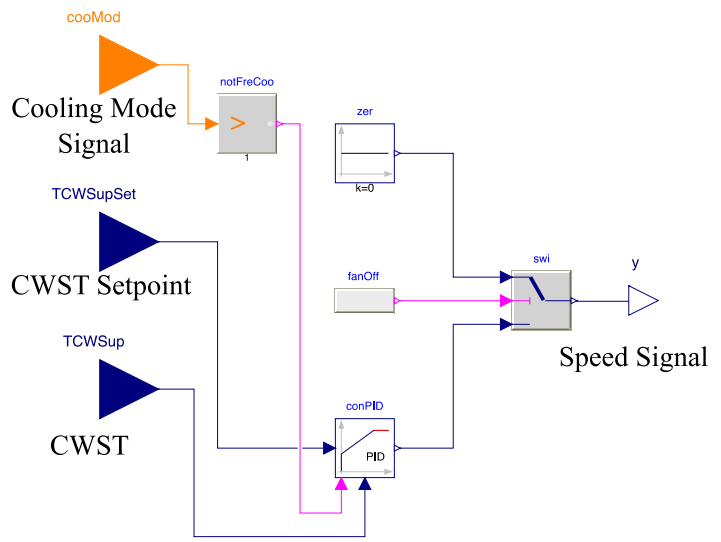

(c) Diagram of the fan speed control in the CWST control

Figure 7. Hierarchical Modelica models of the condenser water loop control 


\subsection{System Models}

After implementing the necessary equipment and control models, this section introduces the system model which combines both the physical plant and control system. Several important assumptions are made to simplify the system level model. First, the cooling load in the data center room consists of only heat generation from IT equipment. The heat transfer from envelope and lighting are not considered. Second, the cooling load in the data center is assumed to be constant and equally distributed into two zones (158 $\mathrm{kW}$ in each zone). Each zone is cooled by a separate AHU. This assumption is reasonable because the measured heat transfer and power for the two AHUs are almost identical. Third, each zone is modeled as an ideally-mixed volume by assuming the air in the data center room to be completely mixed, because our focus here is the backend cooling system instead of air flow distribution in the room. Forth, the underfloor plenum is modeled using a lumped resistance model instead of a detailed air flow model. Last, communication and computation in the control system are assumed to be instantaneous.

As shown in Figure 8, the integrated system model is composed of two parts: the cooling system and the control system. The cooling system is shown at the right side, where the red solid lines represent the condenser water loop, the blue solid lines represent the chilled water loop, and the yellow lines represent the air loop. The controls are displayed on the left side of Figure 8, and include the cooling mode control, and equipment-level controls such as the condenser water loop control, the chilled water loop control, and the air loop control.

Each component model that formulates the system model is verified in a simulation example following the procedure used by the Modelica Buildings library [26]. We validated the customized models using analytical verification, which has also been used to validate all individual component models in the Modelica Buildings library. For example, the model for the chiller with two variablespeed compressors is verified by comparing its simulation results with the analytical solutions that are derived for certain steady-state or transient boundary conditions. 


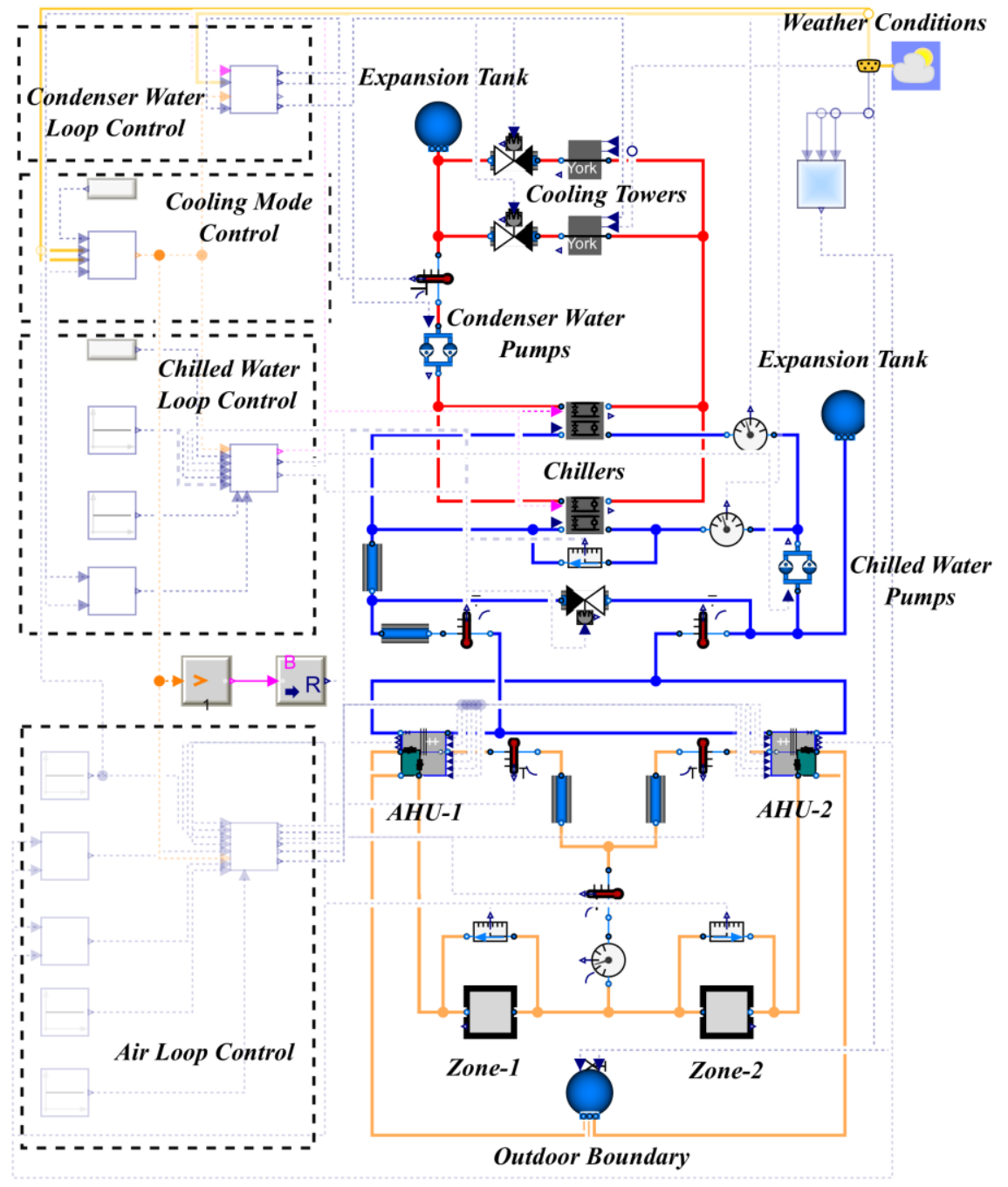

Figure 8. Implementation of the system-level model in Modelica

\section{Calibration}

To evaluate the performance of potential retrofit solutions, we need to establish a baseline model which will predict the performance of the data center cooling system. Figure 9 describes a general procedure to calibrate the baseline model. To automate the calibration process, we formulated it as an optimization problem. The objective of the calibration is to minimize the difference between the model output and the corresponding measurement. The difference is defined by the Normalized Mean Bias Error (NMBE), $e_{N M B E}$. The formulation of the optimization problem is shown in (10). 


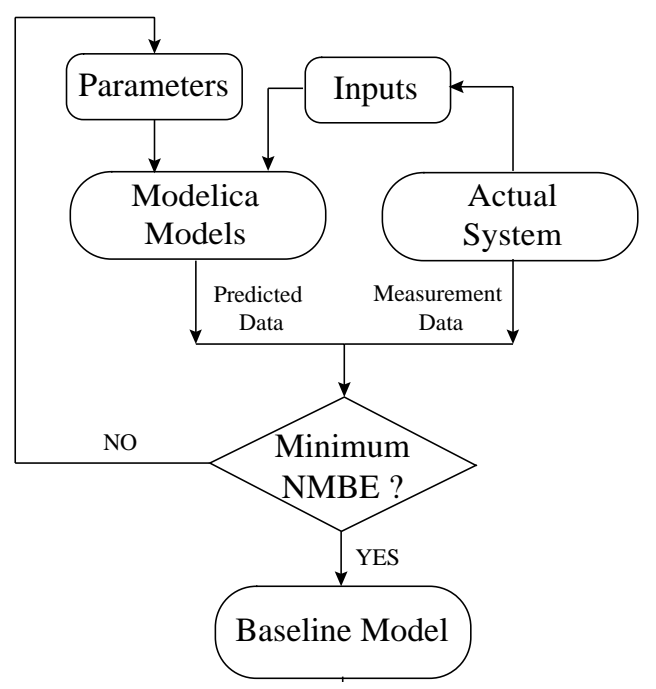

Figure 9. Flowchart of the baseline model calibration

$$
\begin{gathered}
\min \left(e_{N M B E}\right)=\min \left(\frac{\int_{t_{0}}^{t_{0}+\Delta t}|f(p, i n, t)-M(t)| d t}{\int_{t_{0}}^{t_{0}+\Delta t}|M(t)| d t}\right), \\
\text { s.t. } p_{l b} \leq p \leq p_{u b},
\end{gathered}
$$

where $f$ is the calibrated model, which are shown in Table 3. $M$ is the corresponding measurement, in are the inputs for the Modelica models, which can be obtained from measurement data, $t_{0}$ and $\Delta t$ are initial time and length of the calibration period, $p$ are the adjustable parameters of the model, and $p_{l b}$ and $p_{u b}$ are the lower and upper bounds of the parameters $p$, respectively. The optimization problem is solved using the Particle Swarm Optimization algorithm [37] in GenOpt .

To calibrate the baseline model, the abovementioned optimization problem was established and solved for each cooling equipment using measurement data from October 3 to November 3 in 2017. The measurement data were sampled at a 5-minute interval and divided into two sets: the first $80 \%$ were used for calibrating the models, and the remaining $20 \%$ were used to evaluate the calibrated models. Table 3 shows the calibration problems and their results for different equipment. The AHUs are calibrated by adjusting nominal UA values ( $U A_{\text {nominal }}$ ) to predict the outlet temperatures on both air and water side. For the chiller, since the chiller needs two compressors to run at the same time at current cooling load level and we only have the measurement data for the chiller as a whole, we assume the two compressors have the same performance during the calibration. Because the condenser water pump runs at constant speed and the measured power is almost constant, we only calibrated the nominal power $\left(P_{\text {nominal }}\right)$ and nominal head $\left(H_{\text {nominal }}\right)$ instead of the performance curves listed in Table 3.

Relative errors between measurement and prediction are within $8 \%$ for all component models during calibration and evaluation. The system electricity consumption error during the calibration and evaluation period is obtained as $5 \%$ and $6 \%$ after the calibration of the component models.

Although only limited measurement data are utilized for calibration, it is sufficient enough to predict for other seasons. The reasons are listed as follows. First, at the early October, the outdoor 
air temperature is high enough for the system to run at mechanical cooling (PMC and FMC) mode, while at the late October the system can work at FC mode. The measurement data might be in a broad range for calibration. Second, when the mechanical cooling (PMC and FMC) is activated, the performance of chiller is calibrated using the inlet condenser water temperature $\left(T_{c w s}\right)$, the outlet evaporator temperature $\left(T_{c h w s}\right)$. Because both temperatures are controlled within a limited range during the whole year, and the measurement in October covers most of the range (see Table 3 ), it is acceptable to use measurement in October to calibrate chillers. Similar situation happens for pumps and cooling coils in AHUs. For the cooling tower, although the wet bulb temperature in October is much higher than that in February, but it has little influence on the performance of the cooling tower, because in cold days, the cooling towers are shut off.

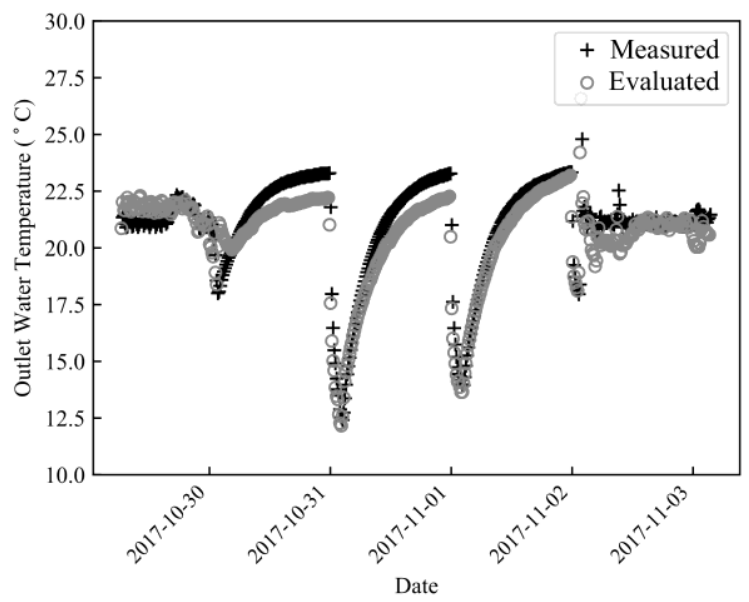

Figure 10. Evaluation results for cooling towers 
Table 3. Calibration and evaluation results

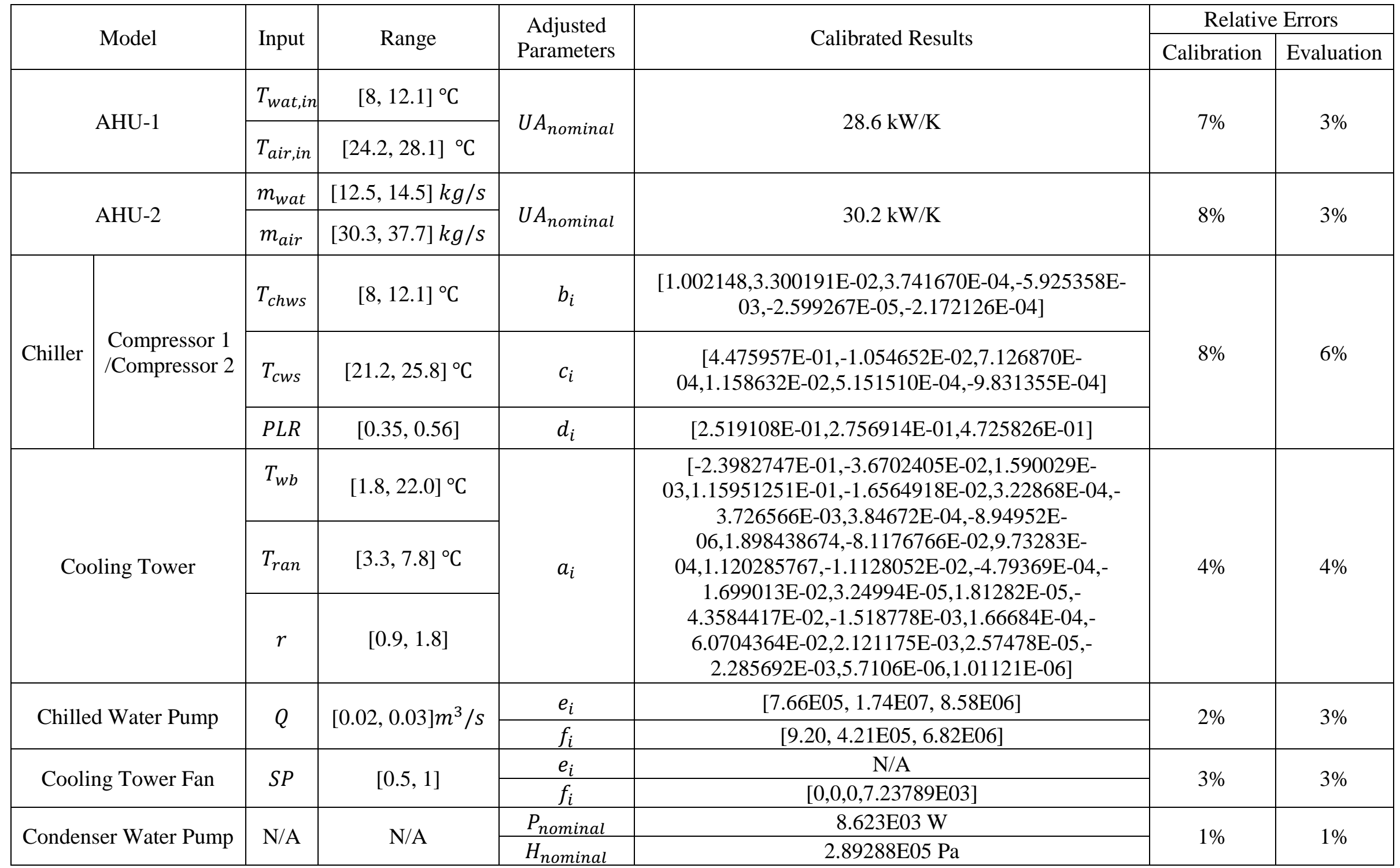




\section{Retrofit Solutions}

We first performed an annual numerical simulation of the baseline system. Based on the analysis of the energy and control performance, we identified several control related issues and proposed corresponding design solutions to improve the control performance. The new design solutions were then examined using the system models. Lastly, we conducted an optimization to further improve the energy saving potentials of the proposed solutions. All the simulations were performed using the local weather data in 2017.

\section{$8 \quad 5.1 \quad$ Baseline System}

The simulation of the baseline system with calibrated equipment models and control settings shows that the cooling system works in FC, PMC, and FMC modes for 6310, 17, and 2433 hours in 2017, respectively. We identified three potential improvements in terms of control and energy efficiency.

First, the cooling coils are degraded possibly because of fouling. The calculated overall thermal conductance according to the measured data is $U A=28.6 \mathrm{~kW} / \mathrm{K}$ for the AHU-1, which is only $37 \%$ of the design value $(U A=77.4 \mathrm{~kW} / \mathrm{K})$ calculated from the manufacture data.

Second, the simulation results show that the cooling system generally operates either in FMC mode or FC mode. However, it rarely works in PMC mode, where the return air is pre-cooled by cold outdoor air. The cooling mode control are defined in (1) to (4). However, the difference between $T_{O A, d p, \text { low }}$ in (2) and $T_{O A, d p, \text { high }}$ in (3) is only $1.1{ }^{\circ} \mathrm{C}$, which is small. As a result, the system will be able to stay in PMC mode only if $T_{O A, d p}$ is between $12.2^{\circ} \mathrm{C}$ and $13.3^{\circ} \mathrm{C}$. Otherwise, it will move to FMC or FC mode.

Third, there is simultaneous heating and cooling in the AHUs, which is caused by the control of the SAT and the chilled water flow rate as described in Section 2.2.2. In FMC mode, it is possible that the SAT is lower than the set point (e.g. the control output signal $y_{2}$ from PID-2 is less than 0.4). This will activate the reheaters in AHU-1, but the CHWST will remain the same because the chiller CHWST reset control can only be activated when $y_{2}$ is larger than 0.4. As a result, the air is overcooled by the chilled water and then heated by reheaters in AHU-1. Besides the SAT control, lacking flow rate control for the chilled water in AHUs also contributes to the simultaneous heating and cooling problem. As described in Section 2.2.2, the speed of the primary pumps is modulated to maintain a fixed pressure difference of $206 \mathrm{kPa}$ between the inlet and outlet of the evaporators, and the bypass valve is adjusted to guarantee that the chilled water through the evaporators is 0.03 $\mathrm{m}^{3} / \mathrm{s}$ all the time. Without direct control of the chilled water through the cooling coils, it can lead to a persistent oversupply or undersupply of chilled water to the cooling coils. The oversupply of chilled water can over-cool the supply air.

\section{$34 \quad 5.2 \quad$ Energy Efficiency Measures}

35 To address the energy inefficiencies identified above, we propose the following three energy 36 efficiency measures (EEMs) for the cooling and control systems. The rest of this paper uses "M" 37 to represent the system with the corresponding EEMs implemented.

\subsection{1 $\mathrm{M}_{1}$ : Clean Cooling Coils}

In system $\mathrm{M}_{1}$, we propose cleaning the fouled cooling coils on both water and air sides. We assume that the UA value of the cleaned cooling coils can be the same as the design nominal UA value. 
more energy consumption than the baseline results because improving the cooling efficiency makes the existing over-cooling problem even worse. After being cleaned, the heat transfer effectiveness of the cooling coils increases, which means under the same CHWST, the cleaned cooling coils cool the supply air to a lower temperature than the fouled cooling coils. As a result, the AHUs with clean cooling coils need additional reheat energy to maintain the same SAT when the water flowrate through the cooling coils is not regulated. For example, when $T_{\text {floor, set }}$ is reset to $23.3{ }^{\circ} \mathrm{C}$, the CHWST can be as high as $12.2^{\circ} \mathrm{C}$. The fouled cooling coils can cool the supply air to around $21.0{ }^{\circ} \mathrm{C}$, and we just need to reheat it to $23.3{ }^{\circ} \mathrm{C}$. However, the clean cooling coils can cool the supply air to around $18.0^{\circ} \mathrm{C}$, and additional energy is expended to bring the SAT to $23.3{ }^{\circ} \mathrm{C}$.

10 Furthermore, the energy of chillers and cooling towers in $\mathrm{M}_{1}$ increases because the heat generated

11 by the reheaters increases the thermal load of the chillers and hence cooling towers.

\subsection{2 $\quad \mathrm{M}_{2}$ : Improve Cooling Mode Control}

13 To increase the operating time of PMC mode, we need to make it easier to move from FMC to PMC and more difficult to move back. To achieve this goal, we propose to increase the $T_{O A, d p \text {, high }}$ by setting it to $15^{\circ} \mathrm{C}$ in system $\mathrm{M}_{2}$. This temperature is a high $T_{O A, d p}$ recommended by ASHRAE for the data center equipment environment [38]. All the other settings remain the same as the 17 baseline system.

18 The annual simulation show that $\mathrm{M}_{2}$ can save $9.0 \%$ of cooling energy compared to the baseline system because the improved cooling mode controller allows the cooling system to operate less in FMC mode, and more in FC and PMC modes. The detailed explanation is as follows:

- The higher cutoff limit of $T_{O A, d p}\left(15^{\circ} \mathrm{C}\right)$ reduces the operational time of FMC mode in $\mathrm{M}_{2}$ (from 2,433 hours to 1,632 hours). Due to a higher $T_{O A, d p}$, the system can stay in PMC mode longer. As a result, $\mathrm{M}_{2}$ operates in PMC mode for 188 hours in the whole year, compared to 16 hours for the baseline system. As the chillers only need to address part of the cooling load in PMC mode, they consume less energy than in FMC mode.

- More importantly, $\mathrm{M}_{2}$ works in FC mode for 6,938 hours, which is 628 hours more than the baseline system. By increasing the time staying in PMC mode, it also increases the possibility of switching from PMC mode to FC mode. For example, as shown in Figure 11, the baseline system works in FMC mode all the time from July 12 to July 15, but $\mathrm{M}_{2}$ can work in FC mode for almost two days in the same period. The $T_{O A, d b}$ is lower than $T_{\text {floor,set }}$ as well as $T_{R A, d b}$ during most of the time. At the beginning of July $12, T_{O A, d p}$ is higher than the high dew point temperature cutoff limit in both the baseline system $\left(T_{O A, d p, \text { high,Baseline }}\right)$ and $\mathrm{M}_{2}\left(T_{O A, d p, \text { high, } M_{2}}\right)$, thus FMC mode is activated in both systems. However, as $T_{O A, d p}$ continues decreasing to $T_{O A, d p, h i g h, M_{2}}, \mathrm{M}_{2}$ can operate in PMC mode, while the baseline system still works in FMC mode. When $\mathrm{M}_{2}$ works in PMC mode, (2) is easily triggered because $T_{O A, d b}$ is lower than $T_{f l o o r, s e t}$, which switches the system from PMC to FC mode. Therefore, with a higher $T_{O A, d p, h i g h}$, it is easier for the cooling system to switch from FMC to PMC mode, and then to FC mode. 

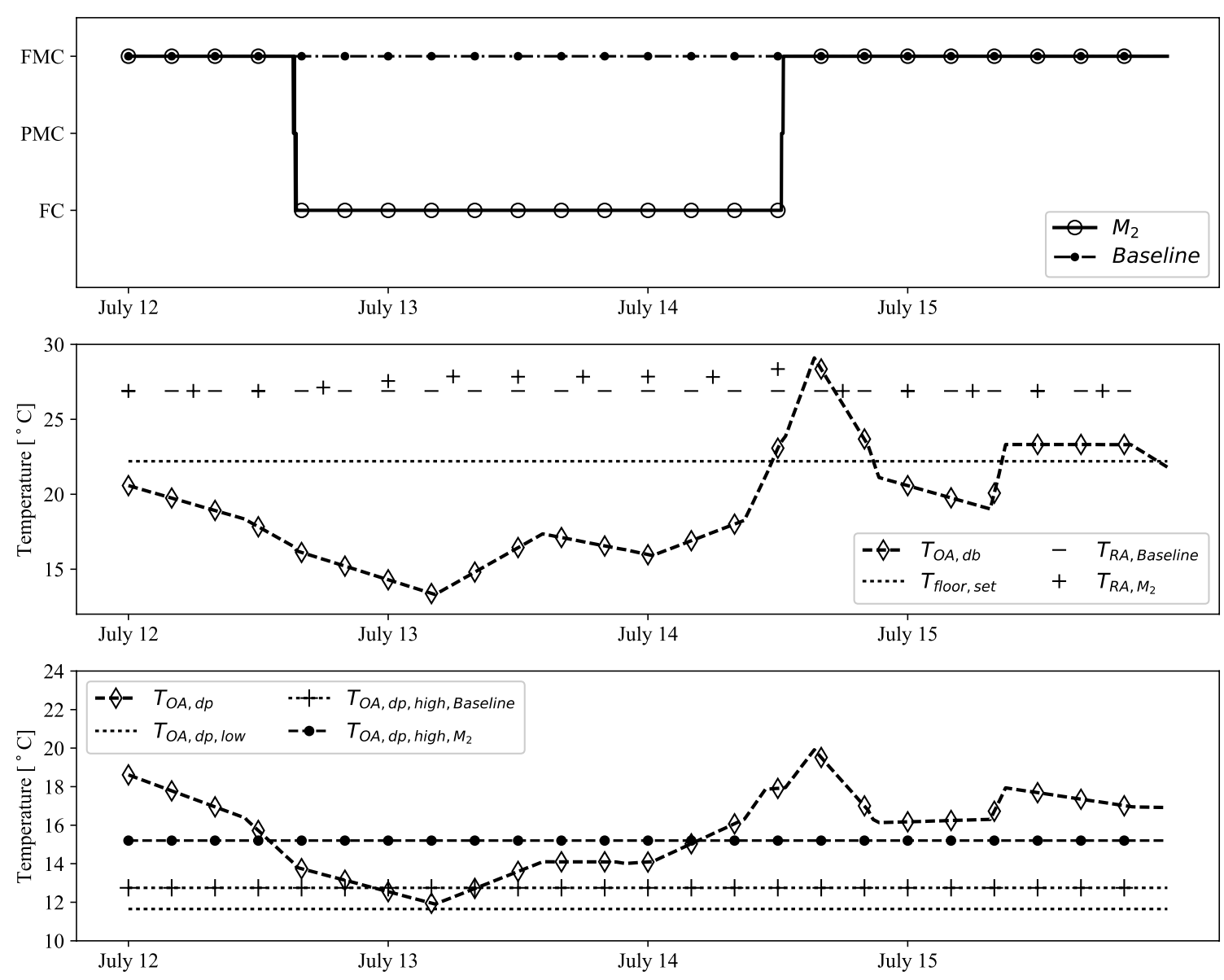

Figure 11. Comparison of the system details in $\mathrm{M}_{2}$ and the baseline system

2 However, increasing $T_{O A, d p, \text { high }}$ might pose challenges for the humidity control of the underfloor 3 air. Figure 12 shows the box plot of the hourly relative humidity $(\mathrm{RH})$ in both $\mathrm{M}_{2}$ and the baseline 4 system. The central rectangular box spans the first quartile to the third quartile, and the dashed line inside displays the median. The lower and upper whiskers represent the 0.1 percentile and the 99.9 percentile, respectively, which means there is only $0.1 \%$ of the data between the minimum and the lower whisker, and $99.9 \%$ of data between the minimum and the upper whisker. In the baseline system, the RH is within the boundary preferred by the operators. However, $\mathrm{M}_{2}$ exceeds the upper bound since it introduces more humid outdoor air in the data center room for free cooling, and the cooling coil in the AHUs has a very limited capacity for dehumidification with a design sensible 11 heat ratio of 0.99 . 


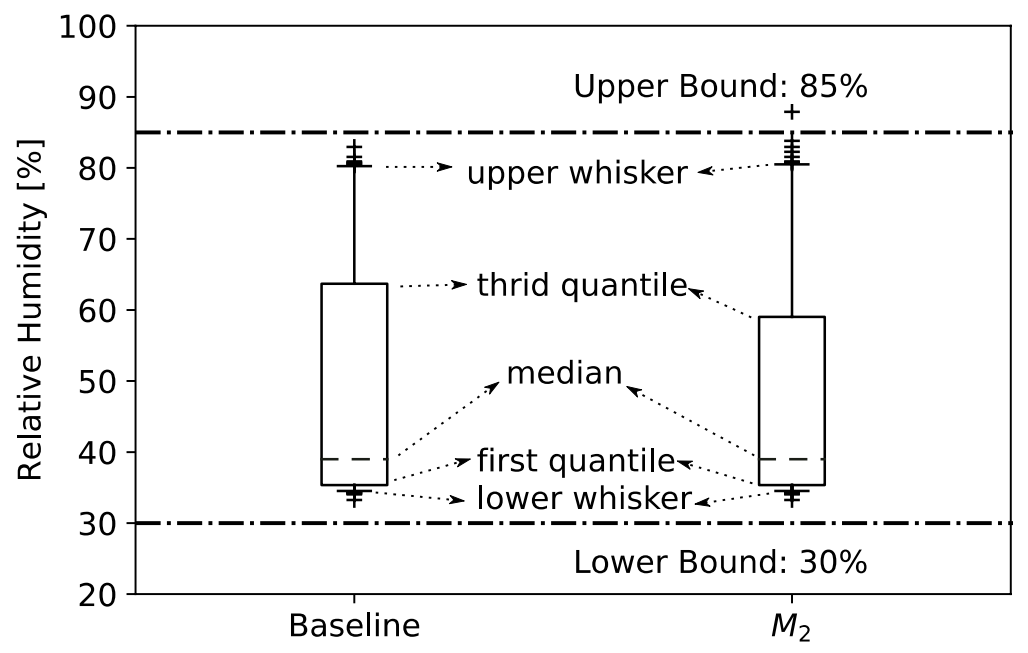

Figure 12. RH of underfloor air in $\mathrm{M}_{2}$ and the baseline system

\section{$3 \quad$ 5.2.3 $\mathrm{M}_{3}$ : Improve SAT Control}

4 To mitigate the problems of simultaneously heating and cooling in the AHUs, we propose adding 5 a two-way valve on the waterside of cooling coils to regulate to maintain the SAT in PMC and 6 FMC modes in system $\mathrm{M}_{3}$. Instead of maintaining a constant differential pressure between the inlet 7 and outlet of the evaporators, $\mathrm{M}_{3}$ adjusts the speed of the primary pumps to maintain a fixed 8 differential pressure of $83 \mathrm{kPa}$ between the inlet and the outlet of the cooling coils. The bypass 9 valve in the common leg is adjusted to achieve a minimum flow rate through evaporators. The 10 above proposal will regulate the amount of chilled water passing through the cooling coils to avoid 11 an oversupply of chilled water and reduce simultaneous heating and cooling in AHUs.

12 Simulation results show that $9.4 \%$ of cooling energy can be saved in $\mathrm{M}_{3}$. Most of the savings are 13 from reheaters. Figure 13 compares the operational status of $\mathrm{M}_{3}$ and the baseline system during 14 July 12 to July 15 . Although the systems operate in the same cooling mode, to track the same SAT 15 setpoint, the reheaters in the baseline system need to be activated, while those in $\mathrm{M}_{3}$ are completely 16 deactivated (see the bottom figure in Figure 13). 

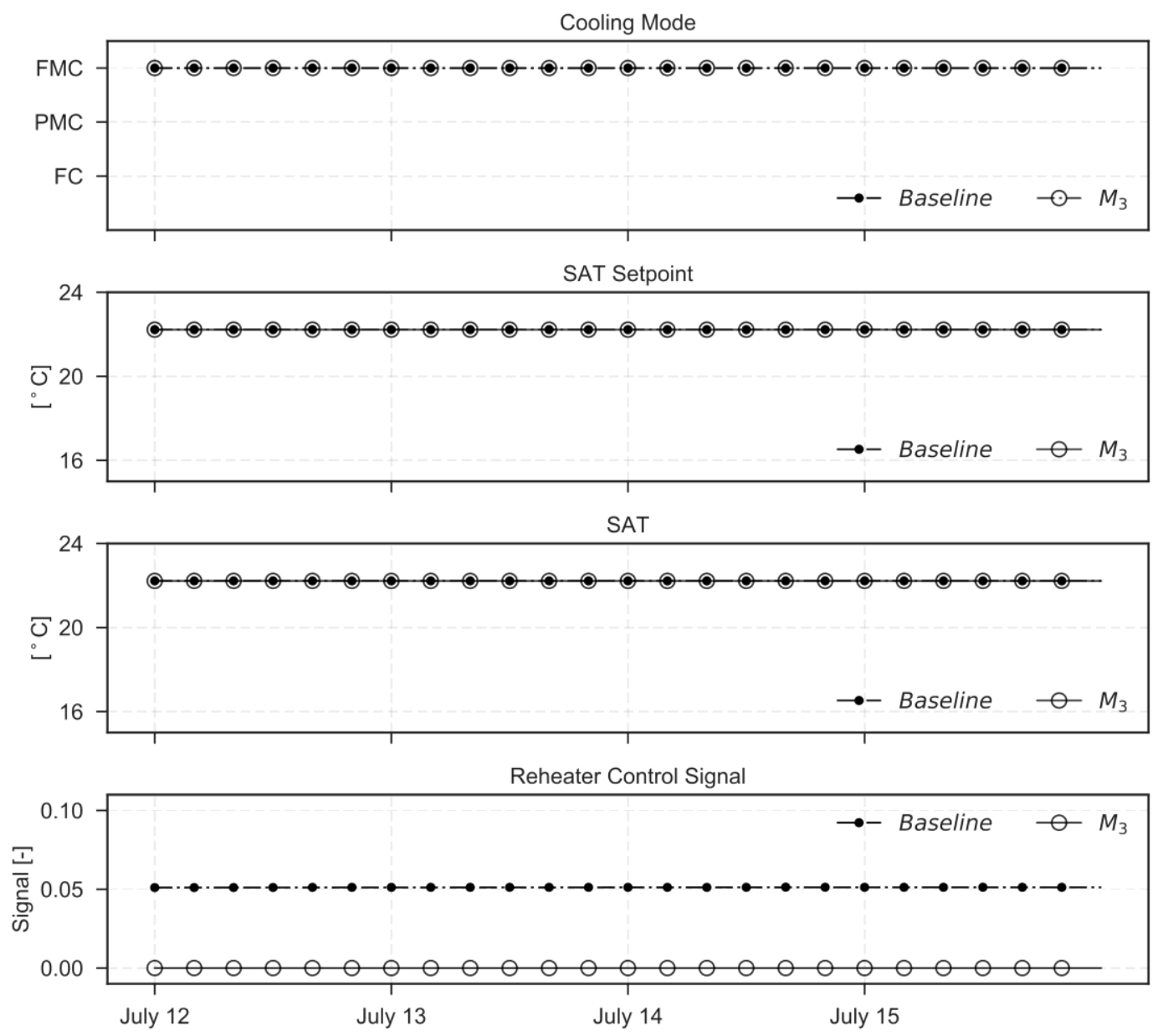

2 Figure 13. Cooling and heating in the AHUs. Simultaneous heating and cooling is avoided in $\mathrm{M}_{3}$

\section{$3 \quad 5.3$ Sequential Search for EEMs}

4 The process of designing and retrofitting real buildings often involves choosing among discrete 5 options, for example, different EEMs. To propose the best EEMs for a building retrofit, engineers need to explore and search the design space of possible EEMs. Genetic Algorithms (GAs) are most commonly used for building energy optimizations [39]. Others seek to develop the Pareto Frontier - the set of cost-optimal solutions over a range of energy savings [40, 41]. However, GAs are typically for optimization problems with large amount of decision variables, such as a large amount

11 Technique $[42,43]$ is utilized to find the most cost-effective retrofit solutions.

\section{$12 \quad$ 5.3.1 Sequential Search Technique}

13 The basic principle of Sequential Search technique is schematically shown in Figure 14. All the 14 proposed EEMs are simulated individually. These simulations comprise an initial iteration of the 15 optimization process. As illustrated in Figure 14, the most cost-effective option (points with 16 steepest slope compared with the optimal design in previous iteration), based on simulation results 17 and energy-related costs, is chosen as the baseline point for the next iteration. The chosen EEM is 18 then removed from future evaluations by the search. Remaining EEMs are simulated in the 
presence of this new baseline point and the iterative process repeats. The method can provide intermediate optimal points, that is, the minimum cost designs at various levels of energy savings, which enables the engineers to make their choice when they are interested in intermediate 4 solutions, rather than a global optimum $[42,43]$.

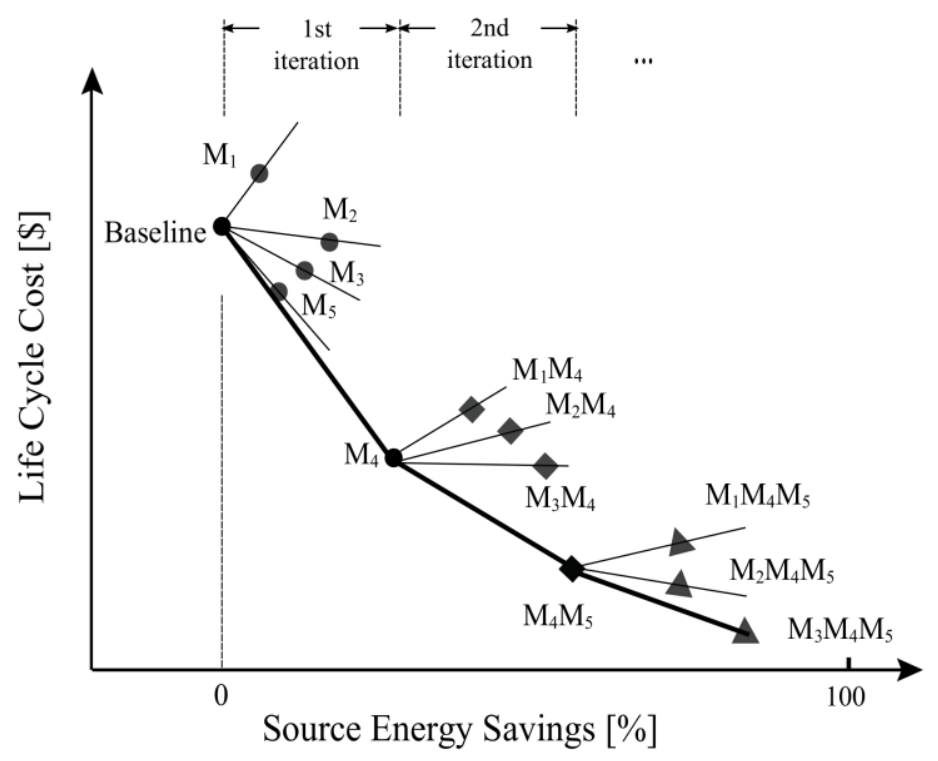

Figure 14. Illustration of Sequential Search Technique

\subsubsection{Results of Sequential Search Technique}

We performed a sequential search technique among the abovementioned three EEMs considering energy savings and LCC. For energy savings, only electricity consumed by the cooling system was taken into account. The LCC is calculated using Eq. (11). The $N$ is the life cycle, and the $r_{d}$ is the real discount rate. The $C_{i, n}, C_{o, n}$, and $C_{m, n}$ are capital cost, operation cost and maintenance cost in year $n$, respectively. In this study, we set $N$ to 40 years, and $r_{d}$ to 0.02 . Capital costs for different measures were estimated by experienced engineers of the analyzed data center, and operation costs were calculated using a variable basic service charge offered by the utility company in Massachusetts [44], which is also shown in Table 4. Maintenance cost for each measure was set to 0 in this study.

$$
L C C=\sum_{n=1}^{N} \frac{C_{i, n}+C_{o, n}+C_{m, n}}{\left(1+r_{d}\right)^{n}}
$$

17 The results of Sequential Search are documented in Table 5. The calculated LCCs are listed in the $186^{\text {th }}$ column, and the energy savings compared with the baseline point of each iteration (optimal 19 solution in previous iteration) are listed in the $7^{\text {th }}$ column. The slopes between the baseline point 20 in each iteration and the evaluated EEMs are shown in the last column, where N/A means the slope 21 is not calculated because the EEM cannot save energy. In Iteration 1, a single EEM is compared 22 with the baseline system. $\mathrm{M}_{2}$ is identified as the most cost-effective solution and then serves as the 23 baseline point for Iteration 2. The simulation results show that the combination of $M_{2}$ and $M_{3}$ is 24 better than that of $\mathrm{M}_{1}$ and $\mathrm{M}_{2}$, because $\mathrm{M}_{1}$ cannot save energy at all. In the third iteration, compared 
with the new baseline point $\mathrm{M}_{2} \mathrm{M}_{3}$, the only combination of $\mathrm{M}_{1} \mathrm{M}_{2} \mathrm{M}_{3}$ has no advantage in terms of both energy savings and LCC.

3 Sequential search among the proposed EEMs shows that $\mathrm{M}_{2}$ is suggested if one EEM is adopted, 4 and $\mathrm{M}_{2} \mathrm{M}_{3}$ is suggested if two EEMs are considered. The combination $\mathrm{M}_{1} \mathrm{M}_{2} \mathrm{M}_{3}$ cannot further 5 reduce energy and LCC compared with $\mathrm{M}_{2} \mathrm{M}_{3}$, and hence is not an effective retrofit option.

6 Table 4. Utility rates used in the studied data center

\begin{tabular}{|c|c|c|c|c|c|}
\hline Month & Price $(\$ / \mathrm{kWh})$ & Month & Price $(\$ / \mathrm{kWh})$ & Month & Price $(\$ / \mathrm{kWh})$ \\
\hline January & 0.10759 & May & 0.06823 & September & 0.08515 \\
\hline February & 0.10632 & June & 0.08505 & October & 0.08360 \\
\hline March & 0.08565 & July & 0.08993 & November & 0.08908 \\
\hline April & 0.07226 & August & 0.08752 & December & 0.10415 \\
\hline
\end{tabular}

7

Table 5. Sequential search process for the proposed EEMs

\begin{tabular}{|c|c|c|c|c|c|c|c|}
\hline $\begin{array}{c}\text { Iteration } \\
\#\end{array}$ & EEM & $\begin{array}{c}\text { Energy } \\
(\mathrm{MWh})\end{array}$ & $\begin{array}{c}\text { Annual Operation } \\
\text { Cost }(\$)\end{array}$ & $\begin{array}{c}\text { Initial Cost } \\
(\$)\end{array}$ & $\begin{array}{c}\text { LCC } \\
(\$)\end{array}$ & $\begin{array}{c}\text { Energy } \\
\text { Savings (\%) }\end{array}$ & Slope \\
\hline \multirow{4}{*}{1} & Baseline & 446 & 39,121 & 0 & $1,070,174$ & 0 & 0 \\
\cline { 2 - 8 } & $\mathrm{M}_{1}$ & 787 & 68,574 & 1,000 & $1,876,875$ & -76.5 & N/A \\
\cline { 2 - 8 } & $\mathrm{M}_{2}$ & 406 & 35,574 & 100 & 973,244 & 8.97 & $-1,080,768$ \\
\cline { 2 - 8 } & $\mathrm{M}_{3}$ & 404 & 35,458 & 110,037 & $1,080,008$ & 9.42 & 104,426 \\
\hline \multirow{4}{*}{2} & Baseline $^{2}$ & 406 & 35,574 & 100 & 973,244 & 0 & 0 \\
\cline { 2 - 8 } & $\mathrm{M}_{1} \mathrm{M}_{2}$ & 656 & 57,208 & 1,100 & $1,566,052$ & -61.6 & N/A \\
\cline { 2 - 8 } & $\mathrm{M}_{2} \mathrm{M}_{3}$ & 358 & 31,481 & 110,137 & 971,315 & 11.8 & $-16,316$ \\
\hline \multirow{2}{*}{3} & $\mathrm{Baseline}$ & 358 & 31,481 & 110,137 & 971,315 & 0 & 0 \\
\cline { 2 - 8 } & $\mathrm{M}_{1} \mathrm{M}_{2} \mathrm{M}_{3}$ & 358 & 31,523 & 111,137 & 973,464 & 0 & N/A \\
\hline
\end{tabular}

\subsection{Optimal Underfloor Plenum Air Temperature Setpoint}

To further investigate the energy saving potentials, we proposed to optimize the cooling system by adjusting the control setpoint of the UPAT in addition to the searched EEMs in Section 5.3. The following section describes the setup and results of the optimization.

\subsubsection{Optimization Problem Setup}

The optimization problem is formulated as:

$$
\min \left(\sum_{\text {con }} E_{\text {con }}\left(T_{\text {floor }, \text { set }}\right)\right),
$$

s.t. $T_{\text {floor }, \text { set }, l} \leq T_{\text {floor }, \text { set }} \leq T_{\text {floor }, \text { set }, u}$

where $E$ is the energy consumption, and the subscript con represents different electricity consumers in the cooling system, including chillers, pumps, cooling towers, and AHUs. The energy consumed by the server fans are considered constant in the optimization problem. The 
UPAT setpoint $T_{\text {floor,set }}$ is chosen as the only design variable in this case study. The subscript $l$ and $u$ are the lower and upper bound. Here we assume that the rack inlet temperature is the same as the UPAT. Thus, we can set $T_{\text {floor,set }, l}=18^{\circ} \mathrm{C}$ and $T_{\text {floor,set }, u}=27^{\circ} \mathrm{C}$ based on ASHRAE's recommended range for rack inlet temperatures [38]. The optimization problem is then solved using exhaustive search or parametric analysis with an increment of $0.1^{\circ} \mathrm{C}$ for the design variable.

\subsubsection{Optimization Results}

7 We performed the optimization on three systems: the baseline system, $\mathrm{M}_{2}$, and $\mathrm{M}_{2} \mathrm{M}_{3}$. The 8 relationship between the $T_{\text {floor,set }}$ and the annual energy consumption for the three systems is 9 shown in Figure 15. The systems with optimal $T_{\text {floor,set }}$ are denoted as Baseline ${ }_{\mathrm{opt}}, \mathrm{M}_{2, \mathrm{opt}}$, and $10 \mathrm{M}_{2} \mathrm{M}_{3 \text {,opt }}$ respectively. The results show that the optimal $T_{\text {floor,set }}$ of Baseline ${ }_{\text {opt }}$ and $\mathrm{M}_{2, \text { opt }}$ is $1125.1^{\circ} \mathrm{C}$, and that of $\mathrm{M}_{2} \mathrm{M}_{3}$,opt is $27^{\circ} \mathrm{C}$. The additional energy savings by optimizing the UPAT are 12 around $20 \sim 25 \mathrm{MWh}$ for all three cases. As a result, the combined energy savings for Baseline ${ }_{\mathrm{opt}}$, $13 \mathrm{M}_{2, \mathrm{opt}}$, and $\mathrm{M}_{2} \mathrm{M}_{3, \mathrm{opt}}$ are $4.5 \%, 14.6 \%$ and $24.2 \%$ compared with the baseline system, respectively.

14 Figure 15 shows that starting from $T_{\text {floor, set }}=18{ }^{\circ} \mathrm{C}$, the energy consumption reduces when 15 increasing $T_{\text {floor,set }}$. However, for the baseline system and $\mathrm{M}_{2}$, when $T_{\text {floor,set }}$ reaches around $1625.1^{\circ} \mathrm{C}$, the annual energy consumption starts to increase. The reason is that when $T_{\text {floor,set }}$ is 17 higher than $25.1^{\circ} \mathrm{C}$, the increased reheat energy is larger than the savings from the chillers and 18 their associated pumps. For example, for the baseline system (Figure 16), when $T_{\text {floor, set }}$ increases from $25.1^{\circ} \mathrm{C}$ to $27^{\circ} \mathrm{C}$, the reheat energy in one year increases from $20.4 \mathrm{MWh}$ to $99.0 \mathrm{MWh}$, but the energy consumed by the chillers only decreases from 89.5 MWh to 87.9 MWh. In $\mathrm{M}_{2} \mathrm{M}_{3}$, the reheaters consume no energy at all even when $T_{\text {floor,set }}$ increases because reheating in the AHUs 22 is avoided.

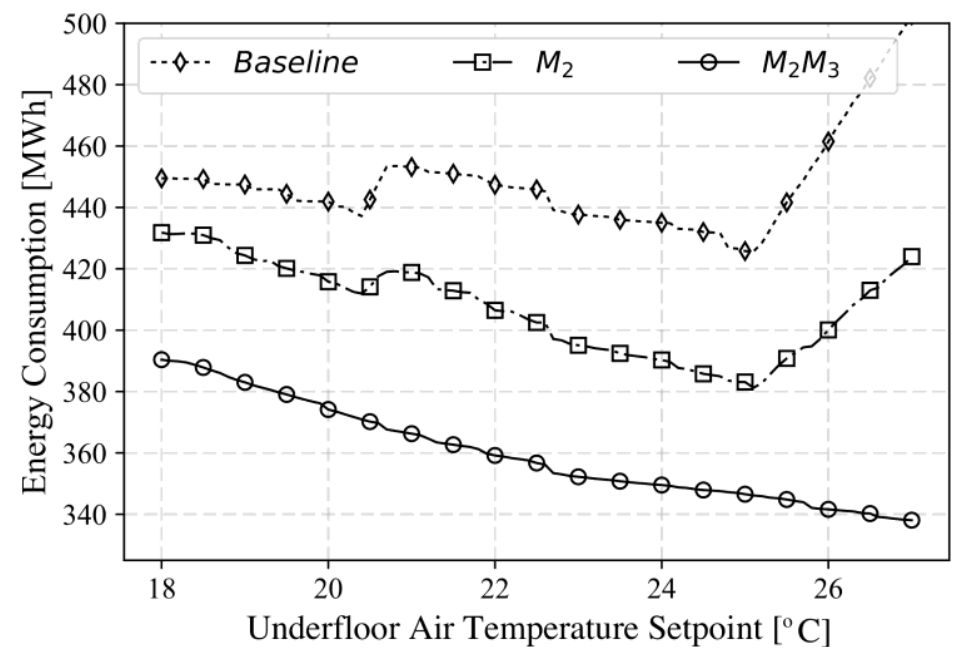

Figure 15. Relationship between $T_{\text {floor,set }}$ and annual energy consumption for different systems 

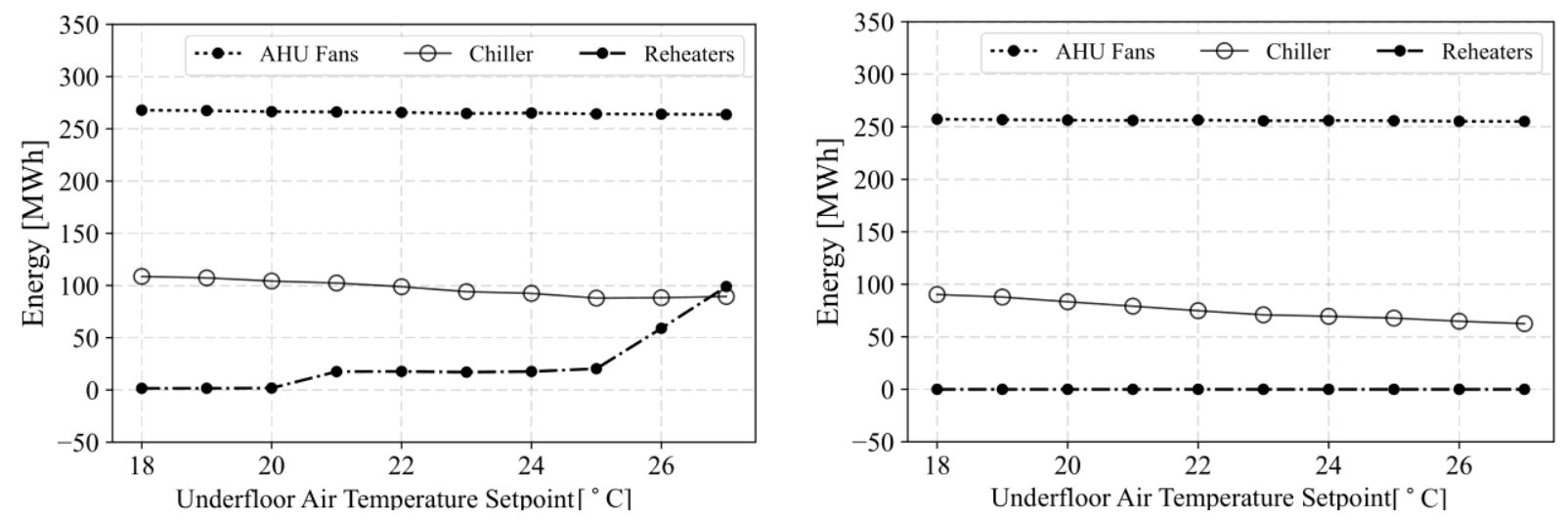

Figure 16. Energy impact of $T_{\text {floor, set }}$ on major cooling equipment: (left) baseline system;

(right) $\mathrm{M}_{2} \mathrm{M}_{3}$

1 It is worth mentioning that the equipment-level control strategies have significant influence on the design space of the above optimization problem. For example, Figure 15 shows that with the baseline reheat control, the baseline system and $\mathrm{M}_{2}$ have local optima around $20.5^{\circ} \mathrm{C}$. The local optima are caused by the activation of reheaters in the AHUs. In $\mathbf{M}_{2} \mathbf{M}_{3}$, the annual energy consumption monotonously decreases as $T_{\text {floor,set }}$ increases, because the reheaters are off for the entire range of $T_{\text {floor,set }}$.

7 Figure 17 shows the operating time under different UPATs during the whole year in the baseline 8 system and three optimal systems. The UPATs are controlled at their setpoints with a tolerance of

$9 \pm 1.5{ }^{\circ} \mathrm{C}$ for about $96 \%$ of the year in the baseline system, and about $99 \%$ in all three optimized 10 systems.

11 Figure 18 compares the RH in the underfloor plenum for a whole year in a box plot with whiskers 12 of 0.1 and 99.9 percentile. The RH in all four systems is within the preferred range. The median 13 RHs in the Baseline opt $_{2}, \mathrm{M}_{2, \mathrm{opt}}$, and $\mathrm{M}_{2} \mathrm{M}_{3 \text {, opt }}$ are lower than that in the baseline system, because the $14 \mathrm{RH}$ decreases as the dry bulb temperature increases if the dew point temperature is the same. 15 Taking the baseline system and Baseline ${ }_{\mathrm{opt}}$ for example, the only difference is that the Baseline opt 16 utilizes $T_{\text {floor, set }}=25.1^{\circ} \mathrm{C}$ instead of $22.2^{\circ} \mathrm{C}$ in the baseline system. Because these two systems 17 have the same $T_{O A, d p}$ thresholds in the cooling mode controller, and their cooling coils have 18 limited capacity of dehumidification, we can assume these two systems have the same dew point temperature in the underfloor plenum for most time. However, UPAT in $\mathrm{M}_{2 \text {,opt }}$ is controlled at $25.1^{\circ} \mathrm{C}$, about $3{ }^{\circ} \mathrm{C}$ higher than the baseline system. Therefore, the median $\mathrm{RH}$ in the Baseline ${ }_{\mathrm{opt}}$ is 21 lower than the baseline system. 

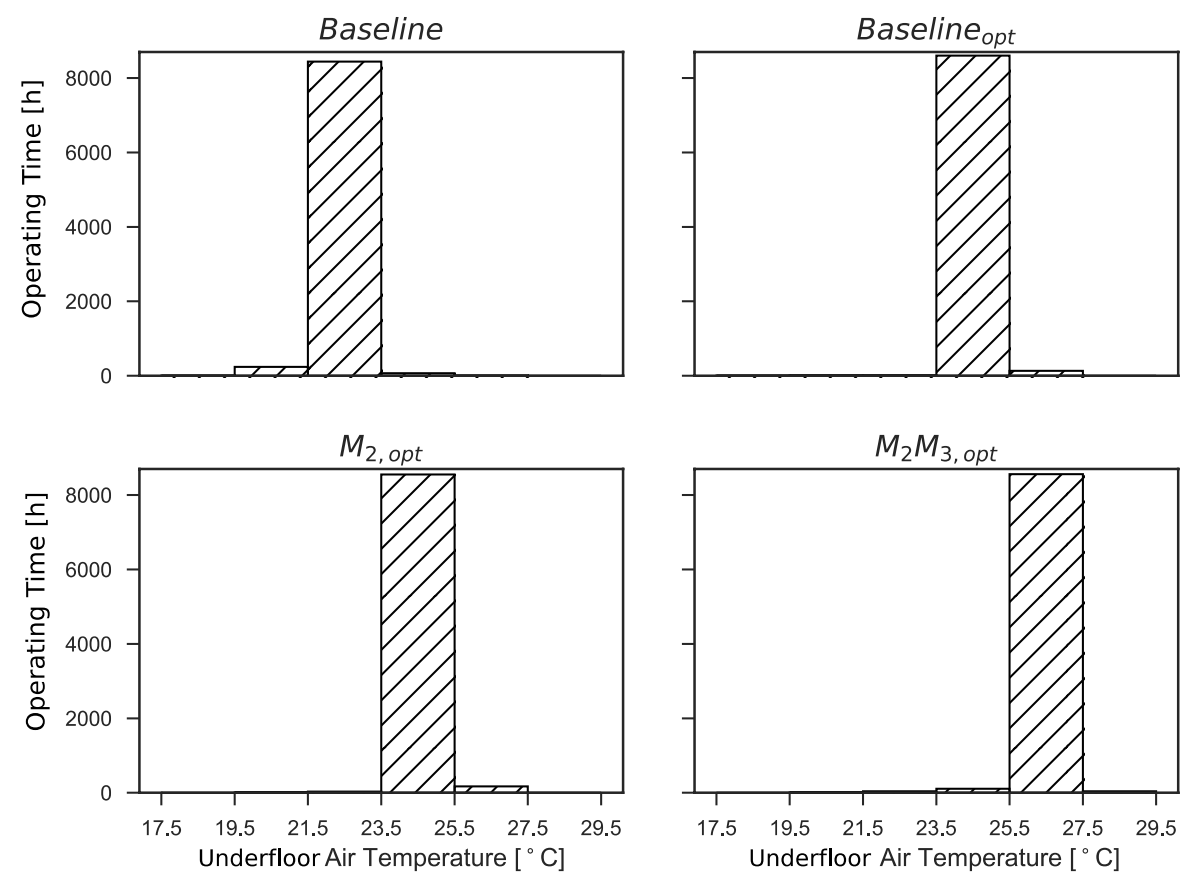

Figure 17. Operating time under different UPATs for four different systems during a year

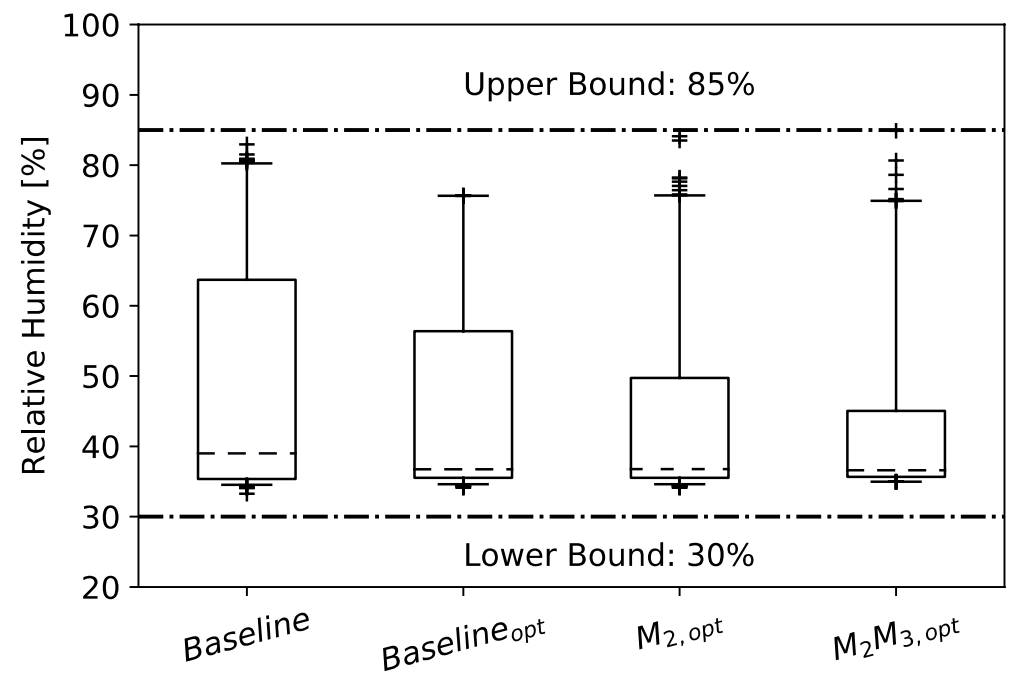

Figure 18. Box plot of the underfloor RH in different systems

2 To understand when the energy savings are achieved in the three optimal systems, we show 3 detailed analysis in Figure 19. The energy savings in Baseline ${ }_{\text {opt }}, \mathbf{M}_{2, \mathrm{opt}}$, and $\mathbf{M}_{2} \mathbf{M}_{3, \mathrm{opt}}$ mostly take 4 place during transition (e.g. October $\sim$ November) and summer seasons (e.g. September). There 
1 are barely energy savings from winter because of free cooling. The maximum daily energy saving

2 in all cases is about $2000 \mathrm{kWh}$, where all the mechanical cooling is totally deactivated.

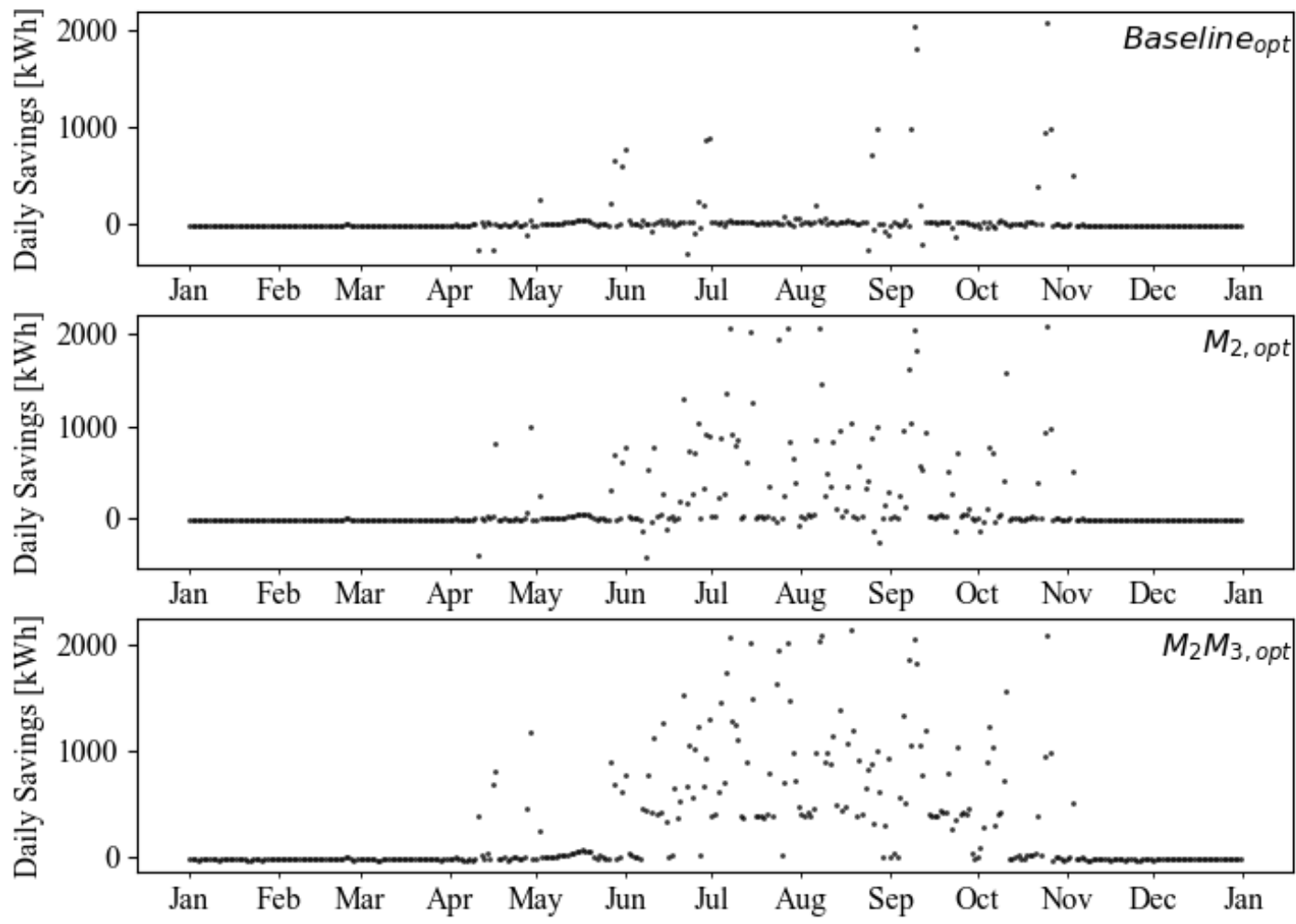

Figure 19. Daily energy savings for different systems

To understand where the energy savings are from, we break down the savings in Baseline opt $_{\text {as }}$ an example shown in Figure 20. For a single day, the cooling tower fans can save up to $150 \mathrm{kWh}$, and all the pumps together can save up to $480 \mathrm{kWh}$. The largest saving is from deactivation of the chiller, which can reduce energy by about $900 \mathrm{kWh}$ in a day. For the AHUs, due to the increase of $T_{\text {floor,set }}$, the fans need to operate at a higher speed to deliver more air to the data center room 11 in order to keep the room at the setpoint. Therefore, during a winter day, the AHU fans in the 12 Baseline $_{\text {opt }}$ can consume $10 \mathrm{kWh}$ more energy than the baseline system due to the increase of the 13 fan speed. For the transition and summer seasons, the AHUs in the Baseline ${ }_{\text {opt }}$ can save up to 500 $14 \mathrm{kWh}$ if the reheaters are deactivated, but can also consume about $500 \mathrm{kWh}$ more energy if the reheaters are triggered due to the control in Section 2.2.2.1. 


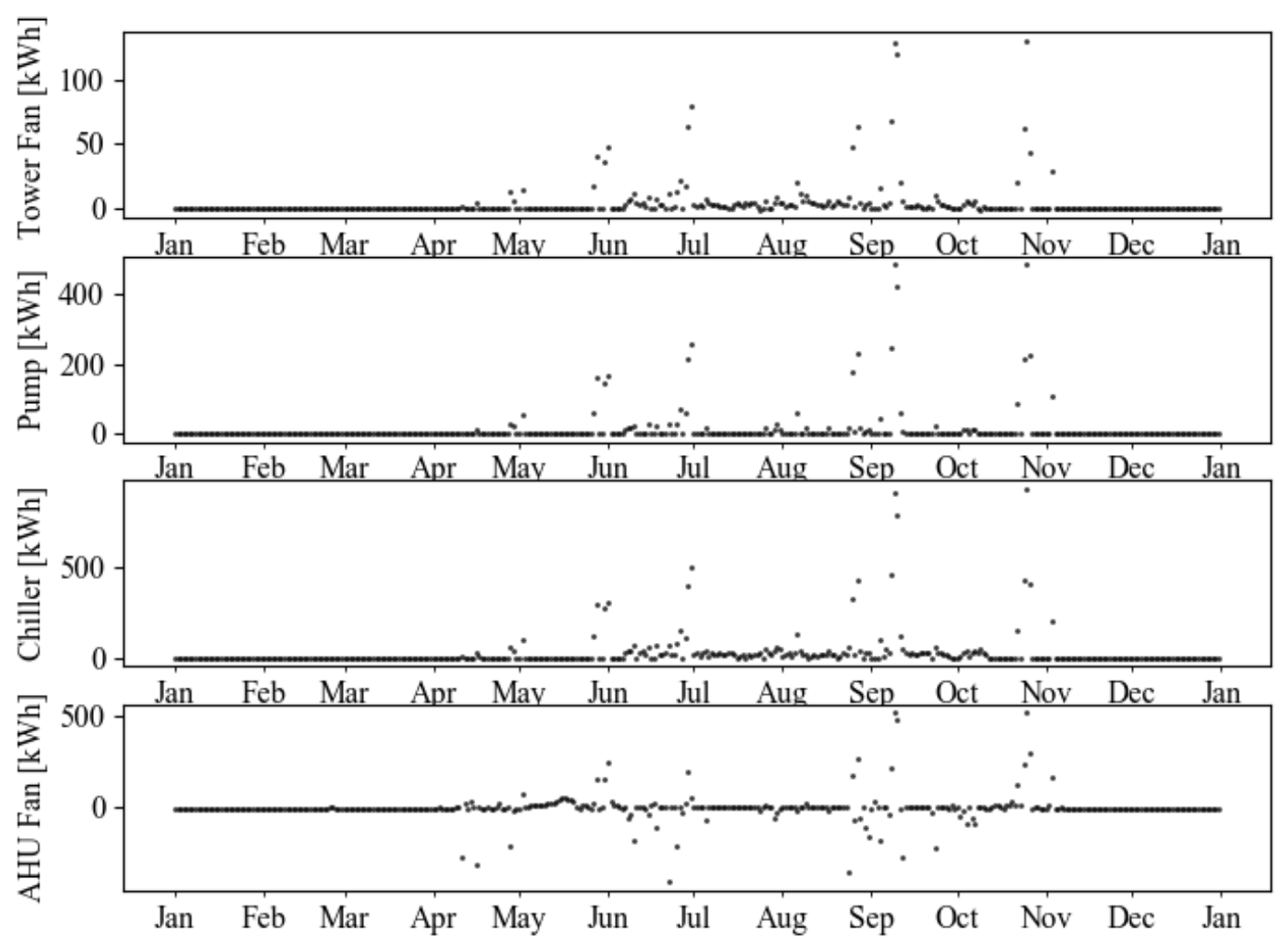

Figure 20. Daily energy savings in Baseline ${ }_{\mathrm{opt}}$

\section{Conclusions}

5 In the present study, an equation-based dynamic modeling and simulation approach is performed 6 to evaluate energy and control performance, to develop EEMs, and to optimize the operation in a medium-size data center located in Massachusetts, United States. The baseline cooling and control systems is built in Modelica and calibrated using measurement data. Three individual EEMs related to energy and dynamic control performance are proposed: $\left(\mathrm{M}_{1}\right)$ cleaning the cooling coils in the AHUs; $\left(\mathrm{M}_{2}\right)$ increasing high cutoff limit of outdoor air dew point temperature in cooling mode controller; $\left(\mathrm{M}_{3}\right)$ improving AHU controls to avoid simultaneous heating and cooling.

12 The intermediate cost-effective retrofit solutions among the proposed EEMs are then identified through the Sequential Search technique. If only one EEM is adopted when budget is limited, $\mathbf{M}_{2}$ is suggested due to its low initial cost and considerable energy savings. If two EEMs are considered, $\mathrm{M}_{2}$ and $\mathrm{M}_{3}$ together can save up to $19.7 \%$ cooling energy. Adopting three EEMs simultaneously is not recommended in this case, because it is hardly a cost effective retrofit.

17 In the end, by optimizing the underfloor air temperature setpoint in addition to the proposed EEMs, 18 the data center can potentially save as much as $24.2 \%$ energy for the cooling system with $\mathrm{M}_{2}$ and $19 \mathrm{M}_{3}$ adopted. The optimal settings for the cooling system can maintain the data center room in an 20 acceptable thermal environment in terms of temperature and relative humidity. The energy savings 21 for all the optimized systems come from summer and transition seasons. 
This case study also demonstrates two important features in Modelica-based tools. One is the capability of complexity management through hierarchical modeling, which supports fast modeling of various user cases. The other is the ability to evaluate discrete control involving delay time and dead band, which are commonly used in the control of the cooling system.

\section{$5 \quad 7 \quad$ Acknowledgement}

6 This research is financially funded by U.S. Department of Energy under the award NO. DE7 EE0007688. This work was also supported by the Assistant Secretary for Energy Efficiency and 8 Renewable Energy, the U.S. Department of Energy under Contract No. DE-AC02-05CH11231.

\section{Reference}

10 1. Dayarathna, M., Y. Wen, and R. Fan, Data center energy consumption modeling: A survey. IEEE Communications Surveys \& Tutorials, 2016. 18(1): p. 732-794.

2. Koomey, J., Growth in data center electricity use 2005 to 2010. A report by Analytical Press, completed at the request of The New York Times, 2011. 9.

14 3. Van Heddeghem, W., et al., Trends in worldwide ICT electricity consumption from 2007 to 2012. Computer Communications, 2014. 50: p. 64-76.

16 4. Wetter, M., A view on future building system modeling and simulation. 2011, Ernest

5. Parolini, L., Models and control strategies for data center energy efficiency. 2012, Carnegie Mellon University.

6. Huang, S., W. Zuo, and M.D. Sohn, Amelioration of the cooling load based chiller sequencing control. Applied Energy, 2016. 168: p. 204-215.

7. Huang, S., W. Zuo, and M.D. Sohn, Improved cooling tower control of legacy chiller plants by optimizing the condenser water set point. Building and Environment, 2017. 111: p. 3346.

8. Jones, R., Seven strategies to improve data center cooling efficiency. 2008, The Green Grid

9. Pan, Y., R. Yin, and Z. Huang, Energy modeling of two office buildings with data center

10. Crawley, D.B., et al., EnergyPlus: energy simulation program. ASHRAE journal, 2000.

11. Kummert, M., W. Dempster, and K. McLean. Transient thermal analysis of a data centre cooling system under fault conditions. in 11th International Building Performance Simulation association Conference and Exhibition, Building Simulation 2009. 2009.

12. Klein, S.A., TRNSYS-A transient system simulation program. University of WisconsinMadison, Engineering Experiment Station Report, 1988: p. 38-12.

13. Lee, K.-P. and H.-L. Chen, Analysis of energy saving potential of air-side free cooling for data centers in worldwide climate zones. Energy and Buildings, 2013. 64: p. 103-112. 
14. Wetter, M., Modelica-based modelling and simulation to support research and development in building energy and control systems. Journal of Building Performance Simulation, 2009. 2(2): p. 143-161

15. Kim, D., et al. Comparisons of building system modeling approaches for control system design. in Proceedings of the 13th International Conference of the International Building Performance Simulation Association (Building Simulation 2013). 2013.

16. Wetter, M., M. Bonvini, and T.S. Nouidui, Equation-based languages-A new paradigm for building energy modeling, simulation and optimization. Energy and Buildings, 2016. 117: p. 290-300.

17. Cho, J., T. Lim, and B.S. Kim, Viability of datacenter cooling systems for energy efficiency in temperate or subtropical regions: Case study. Energy and buildings, 2012. 55: p. 189197.

18. Kim, J.-Y., et al., Energy conservation effects of a multi-stage outdoor air enabled cooling system in a data center. Energy and Buildings, 2017. 138: p. 257-270.

19. Siriwardana, J., S. Jayasekara, and S.K. Halgamuge, Potential of air-side economizers for data center cooling: A case study for key Australian cities. Applied Energy, 2013. 104: p. 207-219.

20. Choo, K., R.M. Galante, and M.M. Ohadi, Energy consumption analysis of a medium-size primary data center in an academic campus. Energy and Buildings, 2014. 76: p. 414-421.

21. Ahuja, N., et al. Data center efficiency with higher ambient temperatures and optimized cooling control. in Semiconductor Thermal Measurement and Management Symposium (SEMI-THERM), 2011 27th Annual IEEE. 2011. IEEE.

22. Fakhim, B., et al., Cooling solutions in an operational data centre: A case study. Applied thermal engineering, 2011. 31(14-15): p. 2279-2291.

23. Hamann, H.F. A measurement-based method for improving data center energy efficiency. in Sensor Networks, Ubiquitous and Trustworthy Computing, 2008. SUTC'08. IEEE International Conference on. 2008. IEEE.

24. Hamann, H.F., V. López, and A. Stepanchuk. Thermal zones for more efficient data center energy management. in Thermal and Thermomechanical Phenomena in Electronic Systems (ITherm), 2010 12th IEEE Intersociety Conference on. 2010. IEEE.

25. Fritzson, P., Principles of object-oriented modeling and simulation with Modelica 2.1. 2010: John Wiley \& Sons.

26. Wetter, M., et al., Modelica buildings library. Journal of Building Performance Simulation, 2014. 7(4): p. 253-270.

27. Wetter, M., et al. Modelica buildings library 2.0. in Proc. of The 14th International Conference of the International Building Performance Simulation Association (Building Simulation 2015), Hyderabad, India. 2015.

28. Wetter, M., A Modelica-based model library for building energy and control systems. Lawrence Berkeley National Laboratory, 2010. 
$129 . \quad H e$, D., et al., Towards to the development of virtual testbed for net zero energy

30. Eisenhower, B., K. Gasljevic, and I. Mezic, Control-oriented dynamic modeling and calibration of a campus theater using Modelica. SimBuild 2012, 2012.

31. Lee, D., B. Lee, and J.W. Shin. Fault Detection and Diagnosis with Modelica Language using Deep Belief Network. in Proceedings of the 11th International Modelica Conference, Versailles, France, September 21-23, 2015. 2015. Linköping University Electronic Press.

32. Tian, W., et al. Optimization on Thermostat Location in an Office Room Using the Coupled Simulation Platform in Modelica Buildings Library: A Pilot Study. in 2018 COBEE conference. 2018.

33. Tian, W., et al., Coupling fast fluid dynamics and multizone airflow models in Modelica Buildings library to simulate the dynamics of HVAC systems. Building and Environment, 2017. 122: p. 269-286.

35. Fu, Y., M. Wetter, and W. Zuo, Modelica Models for Data Center Cooling Systems. Conference: 2018 ASHRAE Building Performance Analysis Conference and SimBuild (BPACS 2018)), September 26-28, Chicago, IL. 2018: ; University of Colorado Boulder. Medium: ED.

36. Hydeman, M. and K.L. Gillespie, Tools and techniques to calibrate electric chiller component models. ASHRAE transactions, 2002. 108(1): p. 733-741.

37. Kennedy, J., Particle swarm optimization, in Encyclopedia of machine learning. 2011, Springer. p. 760-766.

38. Committee, A.T., ASHRAE TC 9.9 Thermal guidelines for data processing enviroments. 2011, USA: American Society of Heating, Refrigerating and Air Conditioning Engineers Inc.

39. Wetter, M., Simulation-based building energy optimization. 2004, University of California, Berkeley.

40. Wang, W., R. Zmeureanu, and H. Rivard, Applying multi-objective genetic algorithms in green building design optimization. Building and environment, 2005. 40(11): p. 1512-1525.

41. Feng, F., et al., Optimizing the topologies of heating, ventilation, and air-conditioning water systems in supertall buildings: A pilot study. Science and Technology for the Built Environment, 2018. 24(4): p. 371-381.

42. Christensen, C., G. Barker, and S. Horowitz. A sequential search technique for identifying optimal building designs on the path to zero net energy. in Proceedings of the Solar Conference. 2004. American Solar Energy Society; American Institute of Architects.

43. Horowitz, S., et al., Enhanced sequential search methodology for identifying cost-optimal 
1 44. Corporation, U. http://unitil.com. 2017; Available from: http://unitil.com. 2 